Edição especial - Sociedade e ambiente no Semiárido: controvérsias e abordagens

Vol. 55, p. 207-237, dez. 2020. DOI: 10.5380/dma.v55i0.72759. e-ISSN 2176-9109

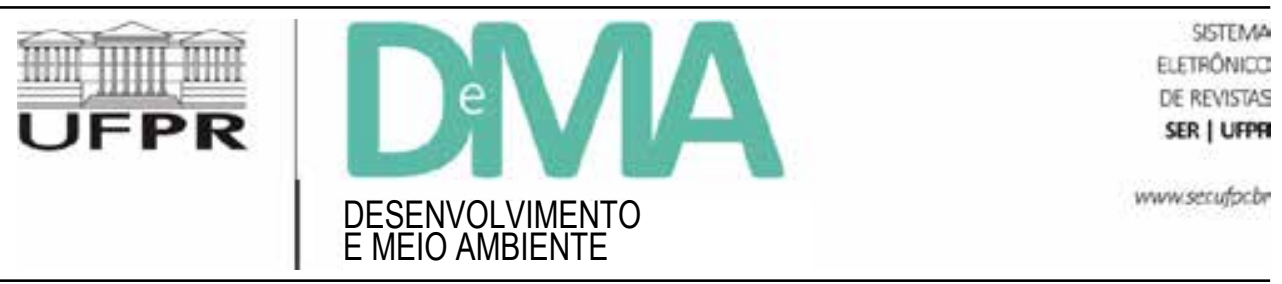

\title{
La construción de un modelo sustenible de trasvase en Brasil: un análisis desde modelo de Tajo-Segura en España
}

\section{A construção de um modelo de transferência sustentável no Brasil: uma análise a partir do modelo Tajo-Segura na Espanha}

\section{The construction of a sustainable transfer model in Brazil: an analysis based on the Tajo-Segura model in Spain}

\author{
Jose Irivaldo Alves Oliveira SILVA ${ }^{1 *}$, Joaquín Melgarejo MORENO² \\ ${ }^{1}$ Universidade Federal de Campina Grande, Campina Grande, PB, Brasil. \\ ${ }^{2}$ Universidade de Alicante, San Vicente del Raspeig, Alicante, Espanha. \\ *E-mail de contato: irivaldo.cdsa@gmail.com
}

Artigo recebido em 9 de abril de 2020, versão final aceita em 19 de setembro de 2020, publicado em 18 de dezembro de 2020.

RESUMEN: La crisis del agua es un proceso planetario que muchas localidades ya enfrentan y otras enfrentarán algún día. Sin embargo, aún es posible pensar en soluciones para promover un modelo de desarrollo regional efectivo, basado en la justicia social, hídrica y ambiental. De esta manera, existe el trasvase del Tajo-Segura del sureste español, que completó 40 años de operación en 2019, y también la transposición brasileña, la del río São Francisco, que comenzó a operar en 2018, solo en uno de los ejes, el Este. Nuestra pregunta en este artículo es la siguiente: ¿en qué medida la presencia de un modelo de gobernanza del agua impacta positivamente en el postrasvase y qué experiencias puede demostrar Tajo-Segura en la transposición de São Francisco? Por lo tanto, al investigar el modelo de Tajo-Segura y el modelo de São Francisco in loco, tener acceso a documentos, legislación y un amplio marco teórico, aplicar el método inductivo y comparativo, fue posible llevar el impacto de una transposición a el desarrollo regional del sureste español y pensar en los problemas que tiene el modelo, o la falta de un modelo, de transponer el "Velho Chico". Por lo tanto, se pensó presentar estas intervenciones en contextos similares, sin embargo, buscando comprender la experiencia de cada una y, principalmente, cómo se desarrolló el modelo de gobernanza en la transferencia de Tajo-Segura. Por lo tanto, fue posible encontrar espacios vacios en el ejemplo brasileño. Entre ellos, se destacó el vacío institucional que transpone el São 
Francisco, lo que dificulta el desarrollo de múltiples usos del agua para el desarrollo regional, además del postrasvase es un problema grave que debe verificarse, esto incluye el saneamiento y recuperación ambiental de la cuenca.

Palabras clave: agua; transvase; gobernanza.

RESUMO: A crise hídrica é um processo planetário que muitas localidades já estão enfrentando e outras vão enfrentar um dia. Entretanto, ainda é possível pensar em soluções para impulsionar um modelo de desenvolvimento regional eficaz, que seja pautado na justiça social, hídrica e ambiental. Dessa forma, apresenta-se a transposição do Tejo-Segura do sudeste espanhol, que completou 40 anos de funcionamento em 2019, e também a transposição brasileira, a do Rio São Francisco, que iniciou seu funcionamento em 2018 apenas num dos eixos, o leste. A nossa questão no presente artigo é a seguinte: em que medida a presença de um modelo de governança hídrica impacta positivamente na postransposição e que experiências o Tejo-Segura pode demonstrar à transposição do São Francisco? Dessa forma, investigando in loco o modelo do Tejo-Segura e o modelo do São Francisco, tendo acesso a documentos, à legislação e a amplo referencial teórico, aplicando-se os métodos indutivo e comparativo, foi possível trazer o impacto de uma transposição para o desenvolvimento regional do sudeste espanhol e pensar nos problemas que o modelo, ou a falta de modelo, da transposição do "Velho Chico" possui. Portanto, pensou-se em apresentar essas intervenções em contextos semelhantes, porém, buscando compreender a experiência de cada uma e, principalmente, como se desenvolveu o modelo de governança na transferência do Tejo-Segura. Sendo assim, foi possível constatar lacunas no exemplo brasileiro. Dentre elas sobressaiu-se o vácuo institucional que se tem na transposição do São Francisco, o que torna mais difícil o desenvolvimento de múltiplos usos da água para o desenvolvimento regional, além do que o postrasvase é uma questão grave a ser verificada, e isso inclui o saneamento e a recuperação ambiental da bacia hidrográfica.

Palavras-chave: água; transposição; governança.

ABSTRACT: The water crisis is a planetary process that many localities are already facing and others will face one day. However, it is still possible to think of solutions to promote an effective regional development model, based on social, water and environmental justice. In this way, there is the transposition of the Tajo-Segura of the Spanish southeast, which completed 40 years of operation in 2019, and also the Brazilian transposition, that of the São Francisco River, which started its operation in 2018, only in one of the axis, the east. Our question in this article is: To what extent does the presence of a water governance model positively impact on post-transposition and what experiences can Tajo-Segura demonstrate in transposing São Francisco? Thus, by investigating the Tajo-Segura model and the São Francisco model in loco, having access to documents, legislation and a broad theoretical framework, applying the inductive and comparative method, it was possible to bring the impact of a transposition to the regional development of the Spanish southeast and to think about the problems that the model, or the lack of a model, of transposing the "Velho Chico" has. Therefore, it was thought to present these interventions in similar contexts, however, seeking to understand the experience of each one and, mainly, how the governance model in the transfer of Tajo-Segura was developed. Thus, it was possible to find gaps in the Brazilian example. Among them, the institutional vacuum that transposes the São Francisco stood out, which makes it more difficult to develop multiple uses of water for regional development, in addition to the post transfer is a serious issue to be verified, this includes the sanitation and environmental recovery of the hydrographic basin.

Keywords: water; transposition; governance. 


\section{Introdución}

El problema del agua es cada vez más fundamental en la planificación urbana y rural de las regiones en diferentes países. De esta manera, buscamos presentar y analizar dos experiencias de intervenciones de infraestructura de agua para mitigar las limitaciones climáticas y la consiguiente escasez de agua estructural, lo que influye en cualquier proyecto de desarrollo que uno desee implementar. Por lo tanto, el problema que se abordará en el presente ensayo es el siguiente: ¿en qué medida la presencia de un modelo de gobernanza del agua impacta positivamente en lo postrasvase y qué experiencias puede demostrar Tajo-Segura en la transposición de São Francisco?

El primero es el trasvase del río Tajo (Figura 1) en la cuenca hidrográfica Segura ubicada en el sureste de España y el segundo es el trasvase del río São Francisco (Figura 2) a varias cuencas en el noreste de Brasil. En ambos casos, la escasez de agua alimenta la necesidad de diseñar una solución que pueda proporcionar una mayor estabilidad del agua para un proyecto de desarrollo regional que incluya la constitución de áreas de regadios y el suministro humano.

Por lo tanto, ya es posible verificar que ambas intervenciones de infraestructura de agua son similares en su operación principal, que es transferir una cierta cantidad de agua de un río a otros en otras cuencas. Sin embargo, en el caso de Brasil, hay dos tomas de agua que resultan en dos acueductos que se transponen entre las cuencas, lo que puede convertirse en algo cada vez más común y necesario ante los cambios climáticos del planeta y la necesidad de distribuir mejor el agua concentrada en ciertos territorios en un claro proceso de balance hídrico.

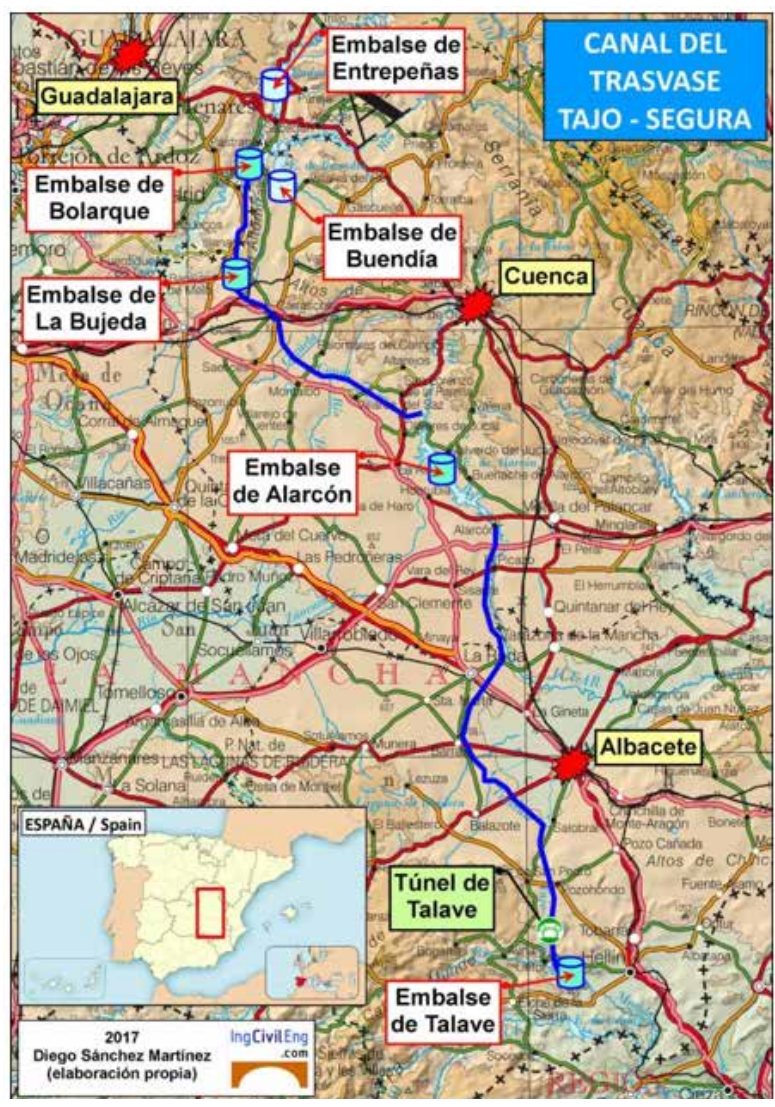

FIGURA 1 - El trasvase del Tajo-Segura.

FUENTE: Imagen trasvase Tajo-Segura: Trazado del Acueducto Tajo - Segura. 2017. Diego Sánchez Martínez (elaboración propia).

Al principio, ya es posible señalar la complejidad de estas operaciones que involucran varios factores, ya sean climáticos, económicos, gubernamentales, legales, sociales y ambientales. Claramente, el proceso que precede a el trasvase con la asignación de recursos para la construcción es un momento igualmente complejo hasta la finalización de las obras. Sin embargo, el postrasvase es un momento crucial, ya que se ocupa de la gobernanza de múltiples factores e intereses relacionados con el 


\section{O novo desenho do São Francisco}

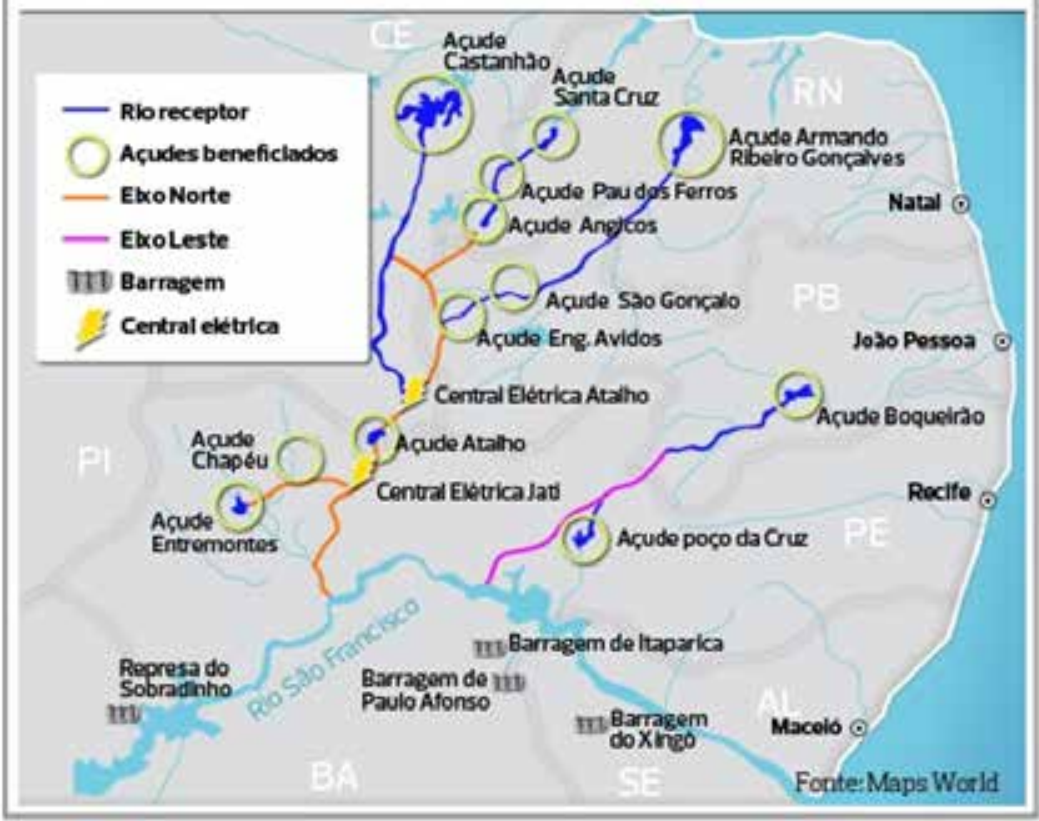

FIGURA 2 - El trasvase del Rio San Francisco, Brasil.

FUENTE: imagen trasvase San Francisco: http://revistagloborural.globo.com/EditoraGlobo/ componentes/article/edg_article_print/0,3916,1709338-2454-1,00.html

propósito principal de estas grandiosas obras para que generen el desarrollo posible.

Por lo tanto, el objetivo de este artículo es presentar estas intervenciones en contextos similares, sin embargo, buscando comprender la experiencia de cada uno y, principalmente, cómo se desarrolló el modelo de gobernanza para la transferencia Tajo-Segura, que completó 40 años de operación en 2019, y visualice un modelo de gobernanza para el trasvase brasileño, que se encuentra al comienzo de la operación del primer eje, llamado este, y un segundo eje llamado norte, que comenzó a operar en agosto de 2020 .
De esta forma, aplicamos el método inductivo y comparativo, se utilizó una extensa investigación bibliográfica y análisis documental, incluyendo leyes y jurisprudencia judicial, durante la pasantía postdoctoral realizada en la Universidad de Alicante. Nos dividimos en 4 secciones, comenzando con la caracterización de las regiones involucradas en el estudio, pasando por los modelos de gobernanza del agua en ambos países y finalmente entrando en la importancia de los trasvases para las regiones estudiadas. 


\section{Caracterización de las regiones}

La Región Nordeste de Brasil, con 1,56 millones de $\mathrm{km}^{2}$ (18.2\% del territorio nacional), comprende la mayor parte de la Región Semiarida de Brasil (Figura 3), que se encuentra en la parte central de esta región, cubriendo los estados de Piauí, Ceará, Río Grande Norte, Paraíba, Pernambuco,
Alagoas, Sergipe, Bahía y parte norte del Estado de Minas Gerais (Región Sudeste), comprende 1,133 municipios con aproximadamente 23,5 millones de habitantes ${ }^{1}$ (Guimarães-Filho et al., 2010). Con una precipitación máxima anual de $800 \mathrm{~mm}$, presentando volúmenes de agua insuficiente en sus manantiales para satisfacer las necesidades de la población. (Guimarães-Filho et al., 2010).

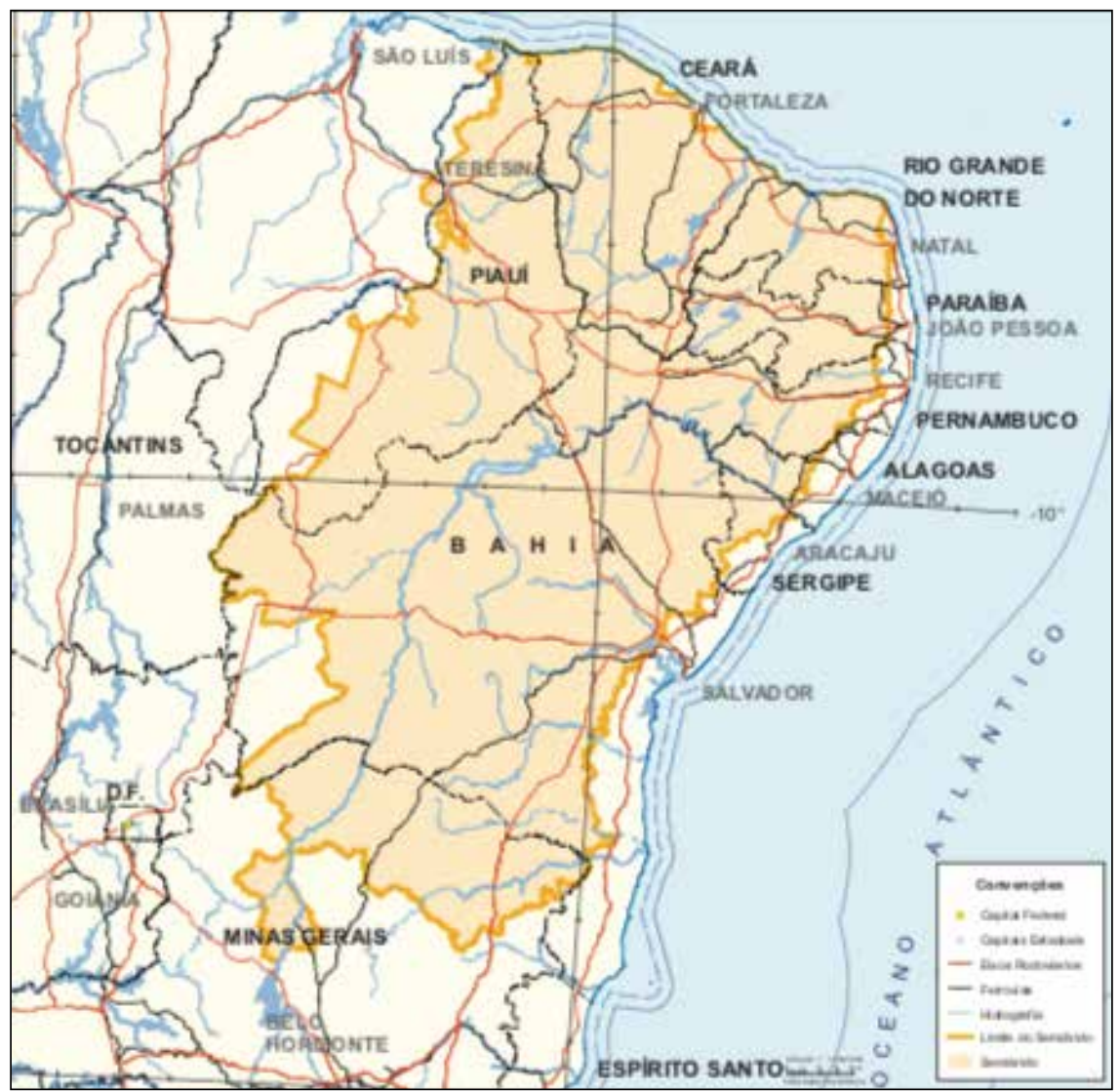

FIGURA 3 - Región semiárida en el noreste de Brasil.

FUENTE: ftp://geoftp.ibge.gov.br/organizacao_do_territorio/estrutura_territorial/semiarido_ brasileiro/Situacao_23nov2017/mapa_Semiarido_2017_11_23.pdf

${ }^{1}$ http://legado.brasil.gov.br/noticias/educacao-e-ciencia/2014/09/semiarido-brasileiro-ultrapassa-23-5-milhoes-de-habitantes. 
Como reflejo de las condiciones climáticas, la hidrografía es frágil, en sus aspectos generales, y es insuficiente para sostener grandes ríos que permanecen perennes en largos períodos de ausencia de precipitaciones. El río São Francisco es una excepción. Debido a sus características hidrológicas, que le permiten mantenerse durante todo el año, el río São Francisco adquiere un significado especial para las poblaciones ribereñas y el área de Sertão.

La región sureste de España es similar en geografía y vegetación frente a las semiáridas brasileñas, aunque tiene una franja costera. Geiger (1973) ya señaló el sureste español como la región más árida de toda Europa, por supuesto, excepto la región del Mar Caspio en el sur de Rusia, que transita entre el árido y el semiárido (López et al., 2001). Ese mismo dijo eso:

Dos puntos capitales deben constatarse, pues ciertas condiciones circuns- tanciales pluviométricas, en una área seca, complican la exposición del problema. En primer lugar, cabe consignar la variabilidad de las precipitaciones, que aquí pueden llegar a una irregularidad extrema. Por este motivo, los valores medios de las precipitaciones son problemáticos; empero no podemos renunciar a ellos. Ahora bien, como complemento debemos dilucidar todo que se relacione con esta variabilidad. (Geiger, 1973, p. 167)

La Figura 4 muestra que el sudeste de España es históricamente una región con poca lluvia, lo que significa que las intervenciones de agua son más relevantes para resolver la mitigación de esta escasez estructural en la región. Las zonas más áridas de España ocupan el equivalente al 2,6\% del territorio del país, incluidas Almería, Alicante y Murcia $^{2}$ en las regiones más áridas con precipitaciones que alcanzan niveles inferiores a $300 \mathrm{~mm}$. La Figura 4 todavía presenta una realidad en la mayor parte de España, un proceso avanzado de desertificación. (Martínez-Valderrama et al., 2012; Ruíz-Puga et al., 2013).
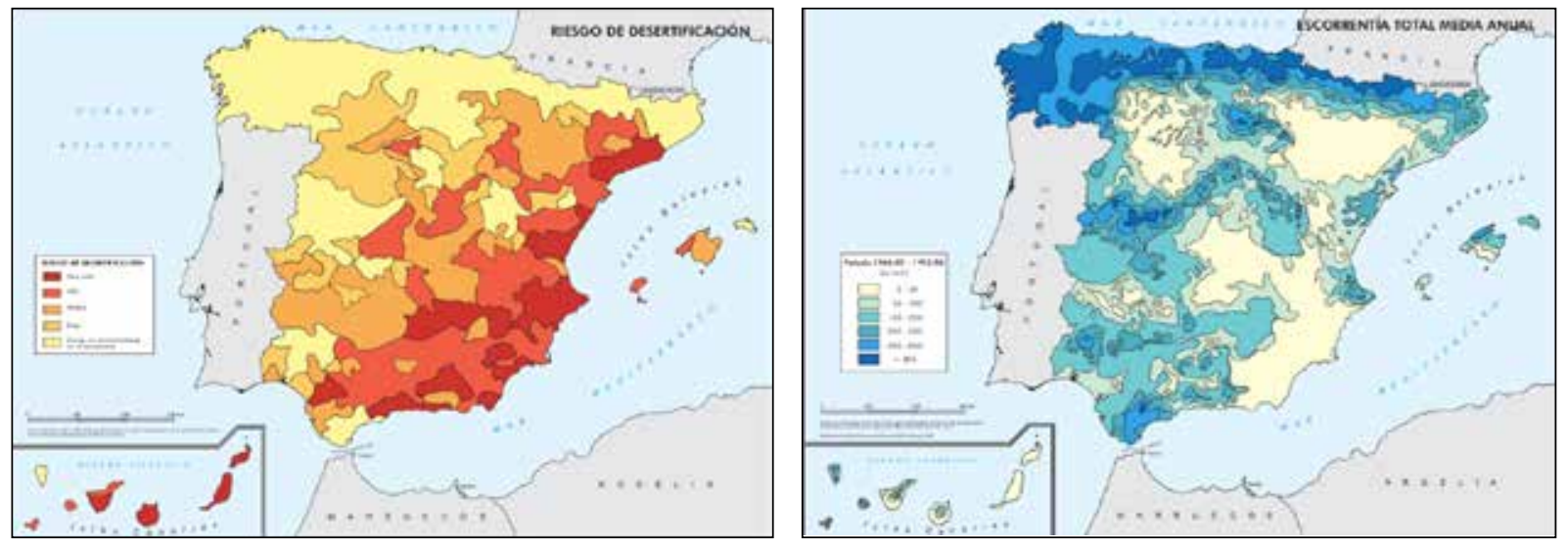

FIGURA 4 - Tasas de lluvia y desertificación en España.

FUENTE: https://www.ign.es/espmap/mapas_ma_eso/MedioESO_Mapa_04.htm; https://www.ign.es/espmap/mapas_riesgos_bach/Riesg_ Mapa_08.htm

${ }^{2}$ https://noticias.eltiempo.es/sequia-espana-las-zonas-mas-aridas/ 


\subsection{Río São Francisco en Brasil}

Conocido como el río de integración nacional, el São Francisco recibió este nombre porque es el camino que conecta el sudeste y el medio oeste con el noreste. El río São Francisco nace en la Serra da Canastra, en Minas Gerais, que abarca unos $2700 \mathrm{~km}$ de longitud, fluye sur-norte a través de los estados de Bahía y Pernambuco, llegando al Oceano Atlántico a través de la frontera entre Alagoas y Sergipe. A lo largo de esta ruta, el río se divide en cuatro secciones: el Alto São Francisco, que va desde su cabecera hasta Pirapora en Minas Gerais; el Médio, desde Pirapora, una sección navegable, hasta Remanso, en Bahía; Submedio, desde Remanso hasta Paulo Afonso, también en suelo bahiano; y el bajo, de Paulo Afonso hasta la boca (Brasil, 2012). Además, la cuenca del río São Francisco tiene una área de drenaje que cubre 503 municipios (Santana, 2012).

La cuenca hidrográfica del río São Francisco (Figura 5) es de gran importancia para el país debido al potencial hídrico que puede explotarse, además de su contribución histórica y económica a la región. El río São Francisco tiene un caudal promedio de $2.980 \mathrm{~m}^{3} / \mathrm{s}$. Alrededor de 16,14 millones de personas, o aproximadamente el 8,5\% de la población del país, habita la cuenca del río São Francisco, con la mayor concentración en Alto (56\%) y Médio São Francisco (24\%). La población urbana representa el $77 \%$ de la población total y la densidad de población es de 22 habitantes / km2. En las otras regiones, se observa un porcentaje de la población de alrededor del 10\% en el Sub-Medio y en el Bajo São Francisco (Brasil, 2012).

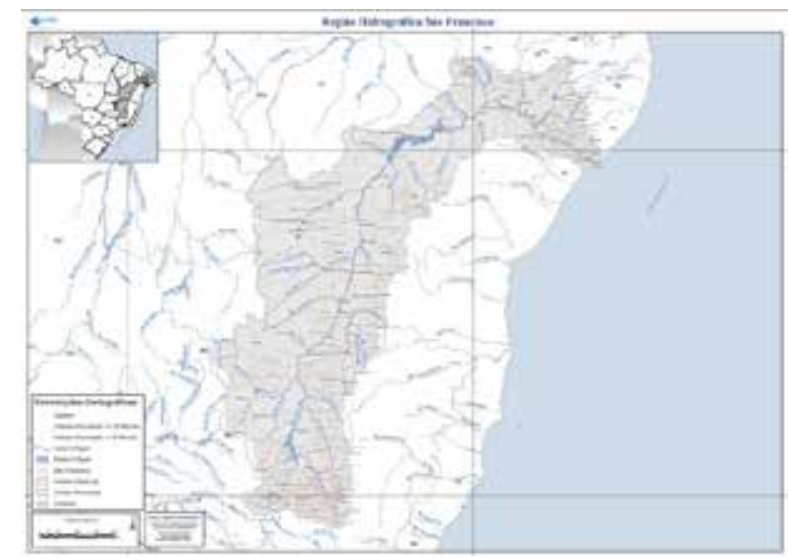

FIGURA 5 - La cuenca de São Francisco, Noreste de Brasil. Fuente: https://mundoeducacao.bol.uol.com.br/geografia/rio-saofrancisco.htm

\subsection{Río Tajo}

El río Tajo (Figura 6) es el más grande de la península ibérica y atraviesa parte de España y todo Portugal hasta llegar al océano. Influye en un total de 10 millones de personas. El tamaño de la cuenca alcanza una capacidad total de alrededor de 14.500 $\mathrm{hm}^{3}$. En lo que respecta al territorio español, está regulado por la Confederación Hidrográfica del Tajo, una organización dependiente del Ministerio de Medio Ambiente y Asuntos Rurales. La transferencia Tajo-Segura deriva parte del flujo del río en la zona suroriental de España. Su curso alto está incluido dentro del Parque Natural Alto Tajo, en la provincia de Guadalajara. Su curso medio-bajo también está legalmente protegido a través del Parque Nacional de Monfragüe, ubicado en la provincia de Cáceres. Más contiguo es el Parque Natural del Tajo Internacional, entre la provincia de Cáceres y Portugal. 


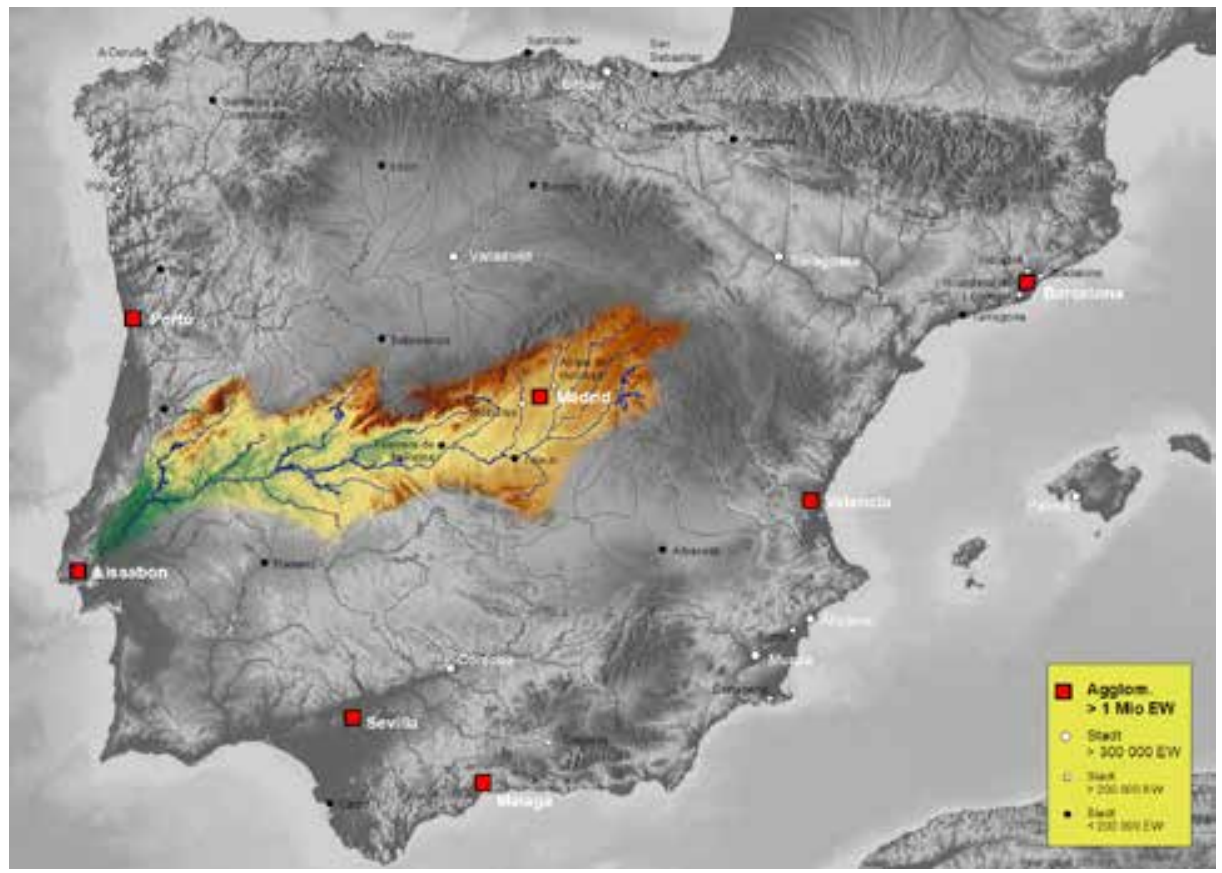

FIGURA 6 - La Cuenca del Rio Tajo.

FUENTE: https://es.wikipedia.org/wiki/Cuenca_hidrográfica_del_Tajo\#/media/Archivo:SpainTajoBasin.png

\section{Modelos de gobernanza del agua en España y Brasil}

\subsection{España}

Las 17 comunidades autónomas de España tienen gobiernos regionales. Los gobiernos regionales tienen poderes en materia de planificación del uso de la tierra, medio ambiente, agricultura, bosques y otras áreas naturales y están involucrados en la gestión de los recursos hídricos. España se dividió en 15 cuencas hidrográficas o distritos de planificación del agua (Figura 7), definidos en la Ley de Aguas de 1985 como "el territorio a lo largo del cual las aguas fluyen hacia el mar en una red de cursos de agua secundarios que convergen en un cauce principal y único" (título II, artículo 14 de la Ley de Aguas de 1985) (Ortega y Hernandéz-Mora, 2009).

Las confederaciones españolas de cuenca son los órganos colegiados básicos que permiten a los usuarios monitorear y actuar en la implementación de la política del agua, y tienen un carácter administrativo, lo que los hace participar en la administración pública (artículo 22, 1, Ley del Agua). Estas confederaciones tienen un amplio poder para actuar en las comunidades autónomas españolas, pudiendo establecer acuerdos y otros pactos. Además de estos, hay dos organismos gubernamentales que participan en la gestión, los Consejos de Gobierno y los Consejos de Exploración que ayudan en la 


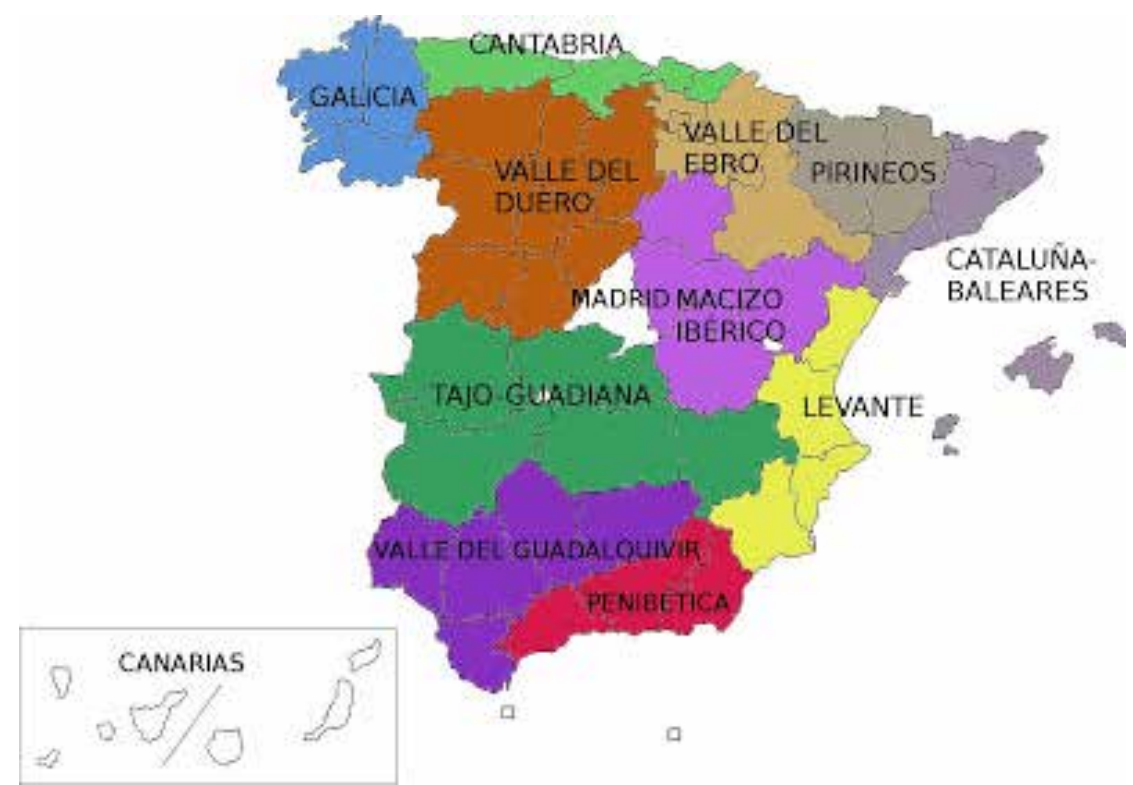

FIGURA 7 - Regiones Hidrográficas de España.

FUENTE: https://www.cronicasdeunmundofeliz.com/2011/12/propuestas-de-division-territorialde.html

toma de decisiones y el proceso de planificación de las cuencas.

También está la Junta de Usuarios y la Comisión de Desembalse que se encarga del régimen de reservorios, acuíferos y cuencas, supervisando y respetando los derechos de los concesionarios. Todavía tenemos la Junta de Obras, un organismo colegiado que recibe y procesa las solicitudes de nuevas obras, y cada confederación tiene un consejo de agua para la cuenca. Además, es importante decir que la confederación solo existirá si la cuenca cruza más de una comunidad autónoma. En el caso de las cuencas intercomunitarias, habrá un Consejo de Autoridades Competentes que funcionará con la atribución de supervisión sobre las demás. Sin embargo, en la parte superior de la "pirámide" española de gobernanza del agua se encuentra el Consejo Nacional del Agua (CNA) (artículo 19, Ley del Agua).

La gobernanza española se adjunta a los siguientes principios, artículo 14:

1. Unidad de gestión, tratamiento integral, economía del agua, desconcentración, descentralización, coordinación, eficacia y participación de los usuarios;

2. Respeto a la unidad de la cuenca hidrográfica, de los sistemas hidráulicos y del ciclo hidrológico;

3. Compatibilidad de la gestión pública del agua con la ordenación del territorio, la conservación y protección del medio ambiente y la restauración de la naturaleza. 


\subsection{Brasil}

Podemos considerar que la gobernanza del agua en Brasil fue verdaderamente institucionalizada y sistematizada desde 1997 con la ley que estableció la Política Nacional de Recursos Hídricos (PNRH), n. 9.433, que también estructuró un Sistema Nacional de Gestión del Agua (SINGREH), que se basa en un enfoque en la participación de los usuarios a través de comités de cuenca. Esta política pública, esencial para el desarrollo de todas las actividades en el territorio nacional, se basa en algunos principios que son (art. 1, Ley 9.433 / 1997):

1. El agua es de dominio público;

2. El agua tiene valor económico o tiene contenido económico;

3. Reconocimiento de la limitación de este activo;

4. La prioridad de la vida humana y de los animales;

5. Gestión que prioriza los usos múltiples del agua;

6. La cuenca hidrográfica debe ser la unidad territorial para la implementación;

7. La descentralización participativa de la gestión.

La ley que instituyó la PNRH estableció las pautas para la gobernanza del agua $\mathrm{y}$, considerando el año de su entrada en vigor, cinco años después de Eco 92, en Río de Janeiro, estuvo influenciada por los valores discutidos en esta conferencia internacional sobre el medio ambiente, previendo el derecho intergeneracional a la disponibilidad de agua de calidad para las generaciones actuales y futuras y sus respectivos usos. Otras leyes instrumentalizan a la administración pública y a la población a fin de recopilar de sus cuerpos la información necesaria que puede apoyar el proceso de toma de decisiones de quienes participan en el proceso de gobernanza del agua. La gobernanza del agua de Brasil también estuvo influenciada por el modelo francês. La Figura 8 muestra las regiones hidrográficas brasileñas donde operan lo SINGREH.

La legislatura brasileña adoptó la gobernanza y gestión adaptativa, cuando estableció como una guía de adecuación de la gestión de los recursos hídricos a las diversidades físicas, bióticas, demográficas, económicas, sociales y culturales de las diferentes regiones del país, es decir debemos verificar cómo son las condiciones locales y regionales. (Ribeiro y Johnsson, 2018).

\section{La importancia de los trasvases en España y Brasil para el desarrollo regional}

En vista de la escasez de agua, es necesario pensar en términos del uso racional de este precioso líquido, y tanto en España como en Brasil la distribución del agua es un problema, ya sea para el consumo humano, ya sea para la agricultura o la industria. De esta manera, lo que llama la atención es la necesidad vital de planificar de manera eficiente el uso y el acceso al agua para que pueda beneficiarse de la multiplicidad de servicios públicos que tiene, lo que agrega a esto un modelo de desarrollo sostenible y vivir con fenómenos climáticos, que son cíclicos y se están creciente. Por lo tanto, con la intención de distribuir mejor la cantidad de agua excedente que existe en cualquier cuenca hidrográfica, el trasvase se ha convertido en una manifestación por excelencia de la planificación del agua segundo Moreno et al. (2009), y se puede decir que se ha 


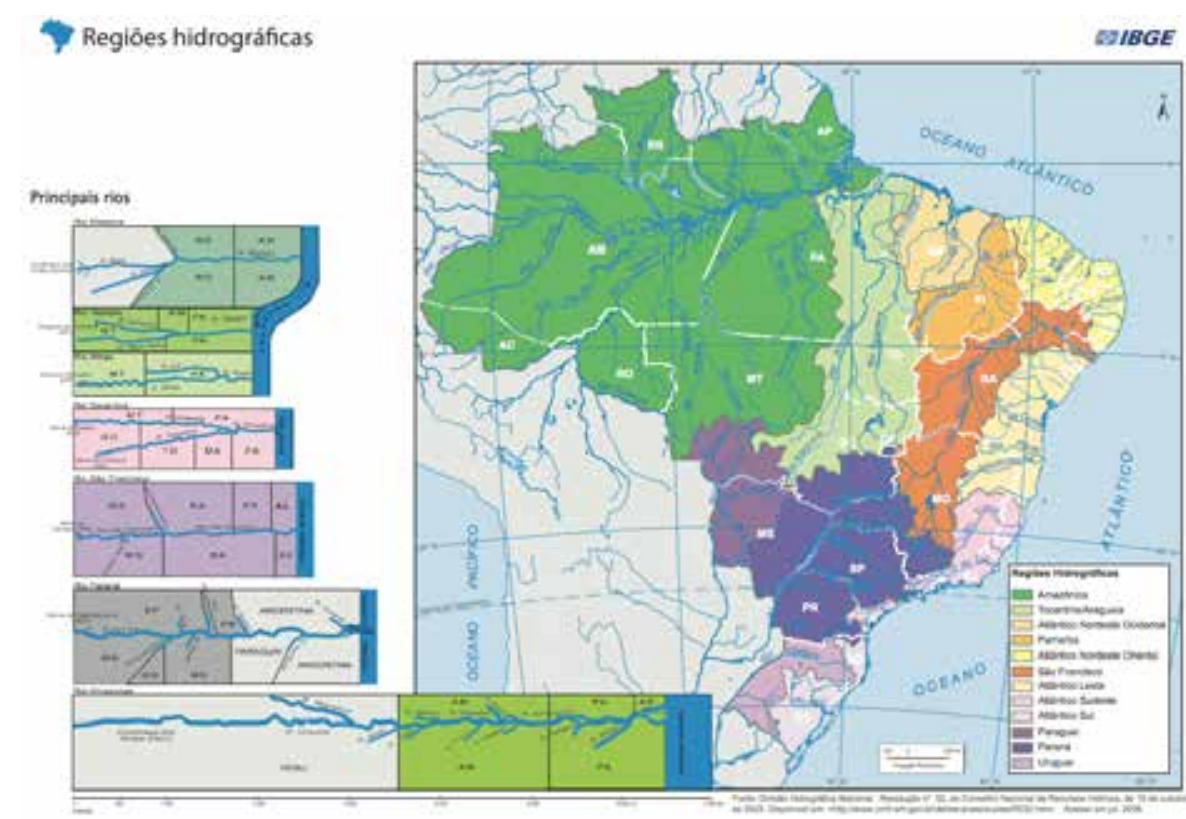

FIGURA 8 - Las regiones hidrográficas brasileñas.

FUENTE: https://atlasescolar.ibge.gov.br/images/atlas/mapas_brasil/brasil_bacias.pdf

convertido en una necesidad en muchos casos, pero las fallas de gobernanza se han identificado como un importante problema.

La transferencia de agua entre cuencas es una intervención de la infraestructura del agua que ya ocurre con cierta frecuencia en todo el mundo (González, 2011). Entre ellos, lo trasvases de Tajo-Segura, en España, Snowy River, en Australia, Lesotho Highland Water Project, en Sudáfrica, Acheloos, en Grecia, Olmos, en Perú, el caso de California, Canadá, la ex Unión Soviética y la Transferencia Norte-Sur en China (Silva, 2016). Las civilizaciones mesopotámicas y egipcias ya han realizado transferencias de agua para la agricultura y los romanos han logrado un nivel sustancial de progreso en este tipo de intervención llegando a canales de $100 \mathrm{~km}$ (González, 2011).
Es posible plantear como una hipótesis muy plausible la posibilidad de que estos mega proyectos hidráulicos se vuelvan aún más frecuentes, en vista del proceso de cambio climático, en el que una de las consecuencias es el desequilibrio hídrico entre las cuencas hidrográficas. Esto puede requerir una intervención de ingeniería para transferir el agua desde donde tiene, quizás en exceso, a donde no. Es importante afirmar que la transposición del agua debe tener un propósito bien definido. González (2011, p. 49) presenta una ruta para este tipo de infraestructura:

- Propósito de la transferencia: agrícola, urbana, industrial, ambiental, etc.

- Relación administrativa entre la transferencia y las cuencas receptoras: podríamos tener transferencias municipales, provinciales 
(estatales), regionales, nacionales o internacionales;

- Iniciativa, financiamiento y recuperación de costos de transferencia: pública, privada o mixta;

- Derechos y situación administrativa de las aguas a transferir y las aguas transferidas;

- Tipos de impactos de transferencia: económicos, ambientales, sociales y políticos.

En el caso de España, así como en Brasil, el proceso que precedió al inicio de las obras fue bastante lento y estuvo impregnado de conflictos, especialmente por los usos políticos de las obras que son fundamentales para la población de las regiones que tienen un nivel de desarrollo desequilibrado con las demás. De hecho, lo que más importa es la discusión de un proyecto amplio que tenga en cuenta el desarrollo nacional basado en una perspectiva de justicia social, equilibrio hidrologico y desarrollo sostenible.

Al principio, un plan hidrológico nacional es esencial como punto de partida. Con base en este plan hidrológico nacional, se promoverá la planificación del uso de las aguas existentes en un territorio determinado, estableciendo un marco de gobernanza que se pueda gestionar con los múltiples actores involucrados. Se observa que España insertó el trasvase del agua como parte de este plan hidrológico nacional, lo que no sucedió con el modelo brasileño, incluida la edición de marcos legales que incorporan esta solución hidráulica como parte del sistema.

Es imperativo pensar en el impacto del agua y los trasvases en el desarrollo regional. Por lo tanto, el marco para el desempeño del suministro de agua para múltiples actividades sin un gran impacto ecológico, o con el menor impacto posible, comienza desde una perspectiva de desarrollo regional, tanto en el noreste brasileño como en el sureste mediterráneo español.

Diniz (2009) señala que el concepto de desarrollo regional incluye una sinergia que comienza desde un polo como un irradiador de procesos y dinámicas de desarrollo, y puede haber un policéntrismo en las decisiones y con varias regiones de polo que se beneficiarían del agua suministrada, mitigando o eliminando un proceso de escasez y expansión de los arreglos productivos en varios sectores, especialmente agrícolas. En el caso español, Alicante, Valencia y Murcia son centros regionales de desarrollo. En el caso del noreste, tenemos ciudades como Caruaru, en el estado de Pernambuco, Campina Grande, en Paraíba, Sobral y Juazeiro do Norte, en Ceará, Mossoró, en Rio Grande do Norte, que son ciudades que irradian estas dinámicas de desarrollo y dependen del agua para promover estos movimientos.

Granito et al. (2007) afirman que el inicio de un proceso de desarrollo regional depende de la activación social de la población local, es decir, de la capacidad de la región para crear un conjunto de pautas políticas, institucionales y sociales capaces de dirigir el crecimiento desencadenado por las fuerzas exógeno Por lo tanto, esta fuerza, a diferencia de las anteriores, es esencialmente endógena y está asociada con el aumento de la autonomía de toma de decisiones de la región, el aumento de la capacidad regional para retener y reinvertir el excedente generado por el proceso de crecimiento, la mejora de la situación social y la preservación del medio ambiente.

Sin embargo, la literatura señala que una perspectiva de desarrollo regional implica necesariamente un carácter multidisciplinario, es decir, varias opiniones que participan en el análisis de fenómenos multicausal; y una base sólida en la preservación 
del medio ambiente (Maia et al., 2012; Mattedi y Theis, 2002; Frey y Wittmann, 2006). Por lo tanto, un enfoque centrado en el desarrollo regional definitivamente no es exclusivamente económico, sino que tiene una dimensión cuantitativa y cualitativa multidisciplinaria.

En este contexto, el agua y sus múltiples usos son factores cruciales en el movimiento de la economía mundial (Silva, 2020). Tenemos dos problemas entre líneas, la existencia de dos ciclos de agua, uno es el ciclo producido en la naturaleza por el movimiento de las masas de aire y la formación de agua en varias formas físico-químicas; y otro es el ciclo urbano, en que la agua se reserva, recolecta y transfiere para diferentes usos, que también pueden incluir los usos reales para la producción rural. Esta segunda modalidad se ajusta a las transferencias de cuencas.

Además, las ciudades en todo el mundo están aumentando de tamaño y $85 \%$ de la población mundial vive en estos espacios (Correia y Farias, 2015). Pero este modelo se ve comprometido por una visión individualista del consumo de recursos. Parece que no se comprende que se viva en un condominio llamado Terra, que tiene límites, y que es necesario encontrar formas de abastecer a la población de manera racional. En este territorio de las ciudades hay precisamente varias lecturas espaciales que tienen repercusiones en la administración local y regional.

En este contexto, hay una variable extremadamente relevante, una crisis de disponibilidad de agua. El agua es esencial en cualquier proceso de desarrollo, a decir que $75 \%$ del agua es utilizada por 6 países más desarrollado. Según Echaid (2013), aproximadamente el $90 \%$ de toda el agua disponible se dirige a dos conjuntos de actividades relevantes: agricultura y industria. El consumo interno representa alrededor del 10\%. Por lo tanto, desde este enfoque, se cree que hay 4 (cuatro) tipos de crisis del agua: crisis de cantidad, crisis de calidad, crisis de acceso y una crisis de ocupación de la tierra. Necesitamos cantidad, disponibilidad, balance hídrico con calidad.

La Figura 9 muestra el estrés hídrico, que es un indicador que muestra el riesgo de escasez de agua.

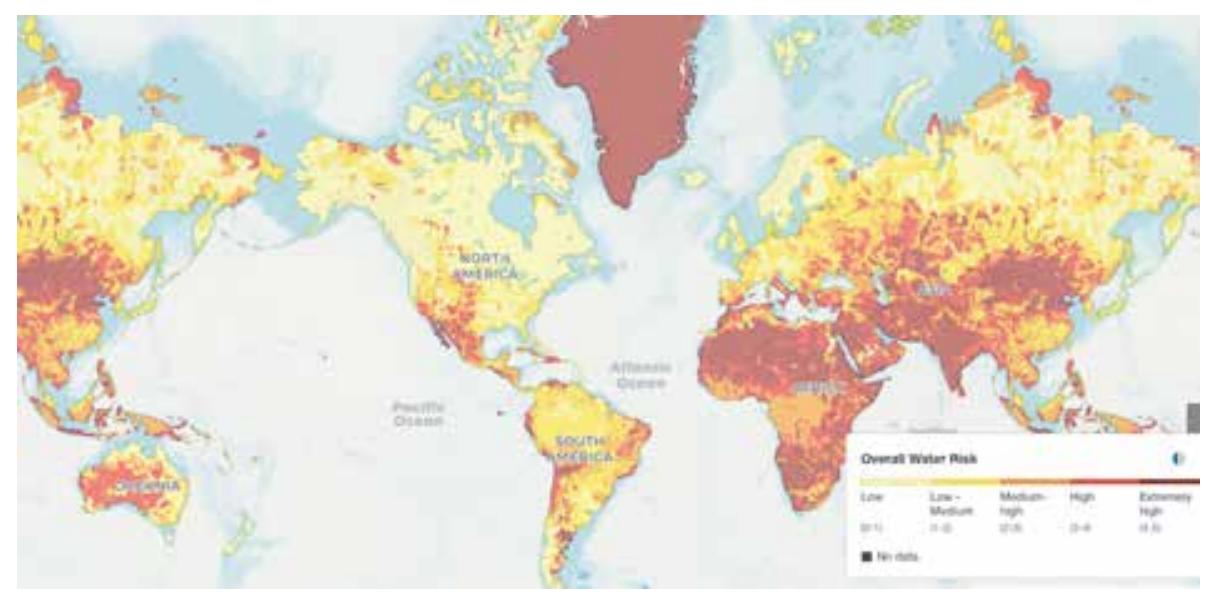

FIGURA 9 - Riesgo de escasez de agua en el mundo. FUENTE: Water Risk Atlas, 2019. 
Es importante tener en cuenta que Brasil aparece en una posición que podría ser cómoda en relación con España y otros lugares, sin embargo, las pérdidas y el desajuste en el saneamiento ${ }^{3}$ (Figura 10) causa alerta, porque a pesar de ser un país privilegiado en términos de recursos hídricos, el equilibrio entre cantidad y calidad es deficitario debido a la contaminación de nuestros manantiales, especialmente los ríos urbanos (Silva, 2020).

Estos datos demuestran la necesidad de pensar en términos de escenarios y planificar la mejor manera de aprovechar al máximo la mejor calidad del agua (Figuras 10 y 14). Martínez y Cuervo (2009) señalan que la transferencia de agua del río Tajo a la cuenca del Segura fue decisiva para poner en práctica proyectos de desarrollo, sin los cuales estos proyectos no se habrían implementado, incluso otros suministros de agua como el agua desalinizada. La Figura 11 demuestra la importancia en términos de volumen de agua de Tajo-Segura para la región sureste de España.
Es posible verificar la importancia del río Taibilla para todo el sistema, en verde oscuro, sin embargo, se verifica cuando comienza la inserción de los caudales del Tajo, de hecho, estos influyeron sustancialmente en el mantenimiento del potencial del complejo de suministro de agua para comunidades y diversas actividades. En rojo, desde 2003 en adelante, la entrada al sistema de agua desalinizada, pero que todavía no permite renunciar a las contribuciones del trasvase. La Figura 12 concentra su información en la cantidad de población de la región estudiada, que es suministrada por varias fuentes, principalmente de Tajo-Segura.

Según Moreno, Ortiz y Aracil (2019, p. 1384), la región sureste de España debe gran parte de su desarrollo y crecimiento económico al sistema MCT (Mancomunidad de los Canales de Taibilla) junto con el trasvase del Tajo-Segura que son decisivos en la supervivencia de la región, así como también en el modelo de la gobernanza adoptada en la que los municipios españoles son las entidades responsables de la implementación, además de lo que

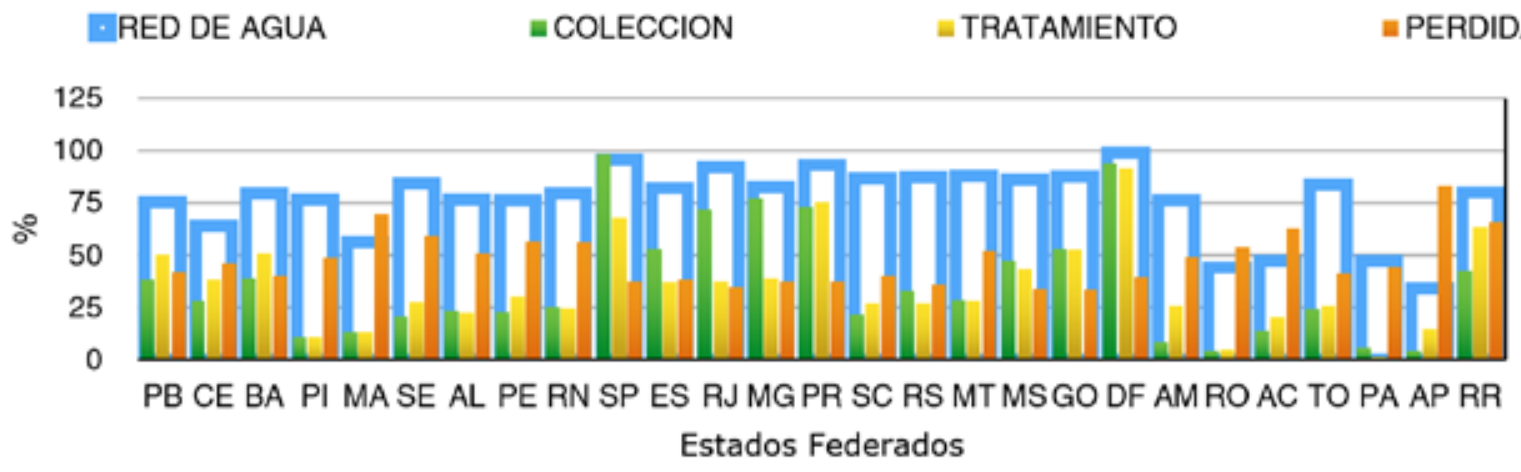

FIGURA 10 - Gráfico de la situación del saneamiento en Brasil.

FUENTE: Sistema Nacional de Informação de Saneamento (Brasil, 2017).

${ }^{3}$ Acceso a agua potable, alcantarillado tratado, drenaje, limpieza urbana y eliminación correcta de residuos. 


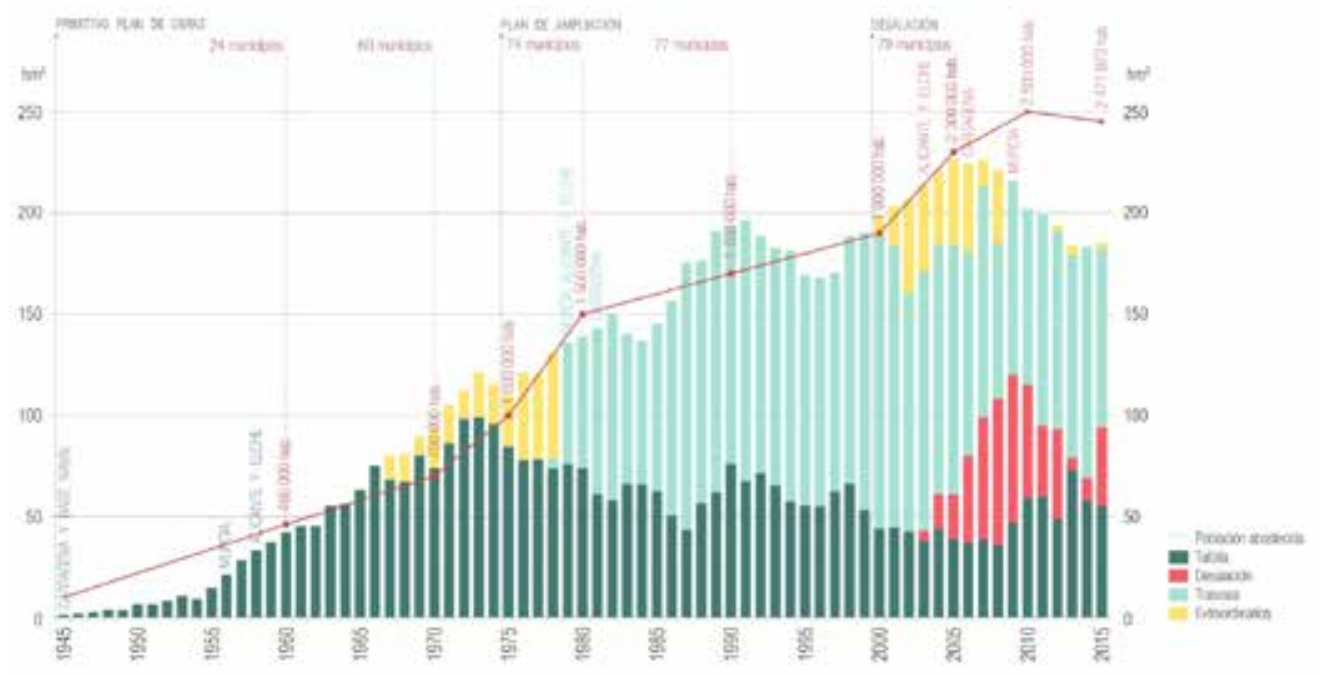

FIGURA 11 - Flujo de agua en el sistema que abastece el sureste español. FUENTE: Instituto del Agua y Ciencias Ambientales.

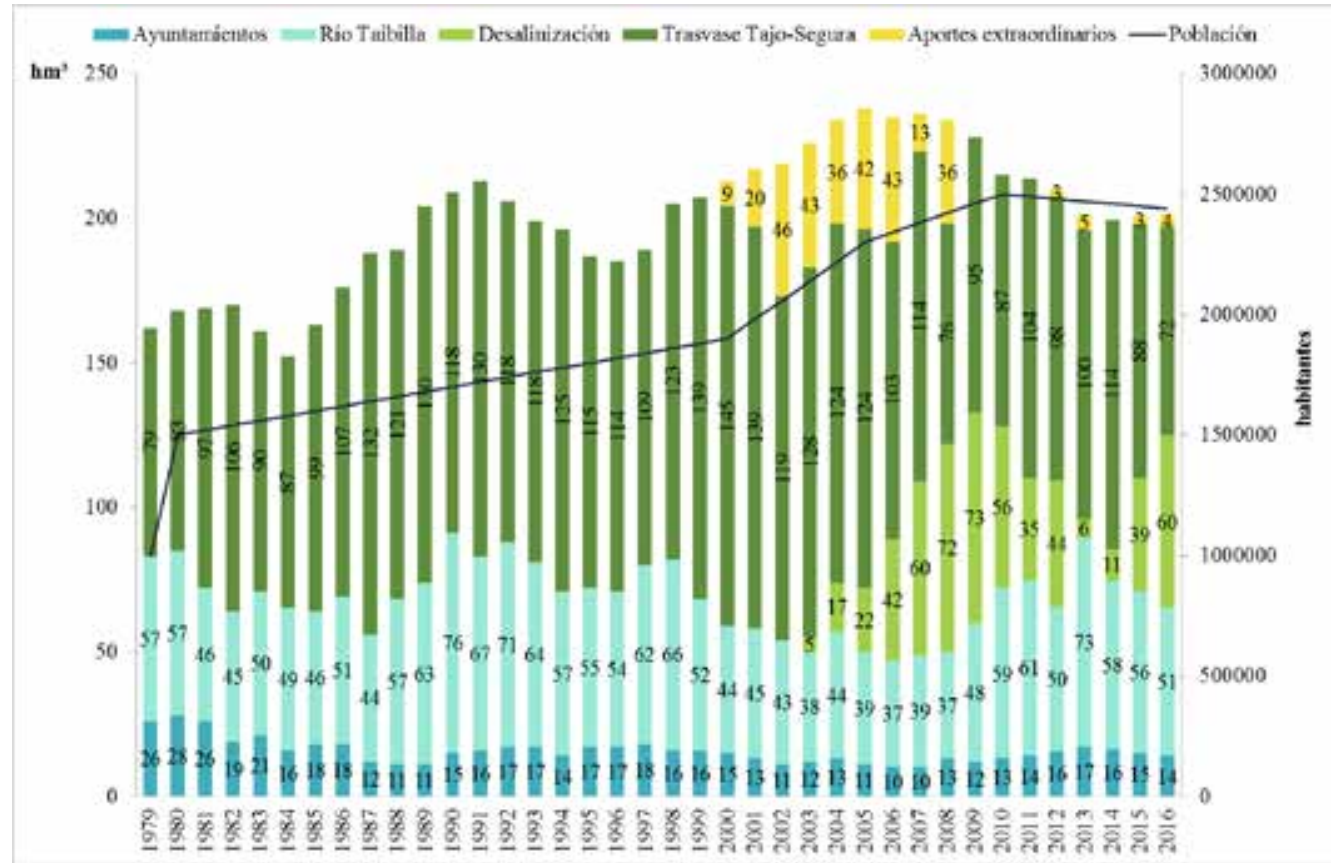

FIGURA 12 - Volumen de suministro de agua a la población.

FUENTE: Instituto del Agua y Ciencias Ambientale. 
según estos autores "el nuevo paradigma concibe el agua como un recurso básico para la vida humana, que debe gestionarse como un bien escaso y con un valor creciente".

Por lo tanto, la escasez de este importante líquido está afectando el costo del servicio y el cambio en el significado del agua de un bien público a una commodity. Aun así, según estos autores, España sufre de escasez de agua y una falta de adaptación a las normas de la Unión Europea en materia de gestión del agua. La Directiva Marco de la Unión Europea 60/2000 aborda la calidad del agua como el objetivo principal considerando el nivel de distribución del agua entre los países de la comunidad, siendo vinculante en todos los países del bloque, principalmente, algunos indicadores, a saber: la tipología de los cuerpos y establecimiento de condiciones de referencia (elementos físico-químicos, hidromorfológicos y biológicos) (Silva et al., 2013). Es interesante señalar algunos aspectos destacados de esta norma europea (Parlamento Europeu, 2000):

- El agua no es un producto comercial como cualquier otro, sino un patrimonio que debe ser protegido, defendido y tratado como tal;

- Es necesario desarrollar una política comunitaria integrada del agua;

- Es necesario continuar integrando la protección y la gestión sostenible del agua en otras políticas comunitarias, como las políticas de energía, transporte, agricultura, pesca, regional y turismo;

- Una política hídrica efectiva y coherente debe tener en cuenta la vulnerabilidad de los ecosistemas ubicados cerca de la costa y los estuarios o en abismos o mares relati- vamente cerrados, ya que su equilibrio está fuertemente influenciado por la calidad de las aguas continentales que fluyen hacia ellos. La protección del estado de las aguas en las cuencas hidrográficas proporcionará beneficios económicos al contribuir a la protección de los recursos pesqueros, incluidos los recursos costeros;

- La aplicación de esta Directiva contribuirá a la reducción gradual de la contaminación del agua;

- Se necesitan principios comunes para coordinar los esfuerzos de los Estados miembros para aumentar la protección de las aguas comunitarias en términos de cantidad y calidad, promover el uso sostenible del agua, contribuir al control de los problemas transfronterizos del agua y proteger los ecosistemas, zonas acuáticas y terrestres y los humedales que dependen directamente de ellas, y para salvaguardar y desarrollar los usos potenciales de las aguas comunitarias;

- La buena calidad del agua asegurará que las personas reciban agua potable;

- El objetivo final de esta Directiva es lograr la eliminación de sustancias contaminantes prioritarias.

La Figura 13 demuestra la importancia desde el punto de vista económico de que existen impactos positivos en las comunidades allí, lo que demuestra un crecimiento considerable en la apertura de nuevos negocios, lo que, según Moreno, Ortiz y Aracil (2019), esta evolución está directamente relacionada con la búsqueda de nuevas fuentes de agua que complementan el sistema deficitario. 


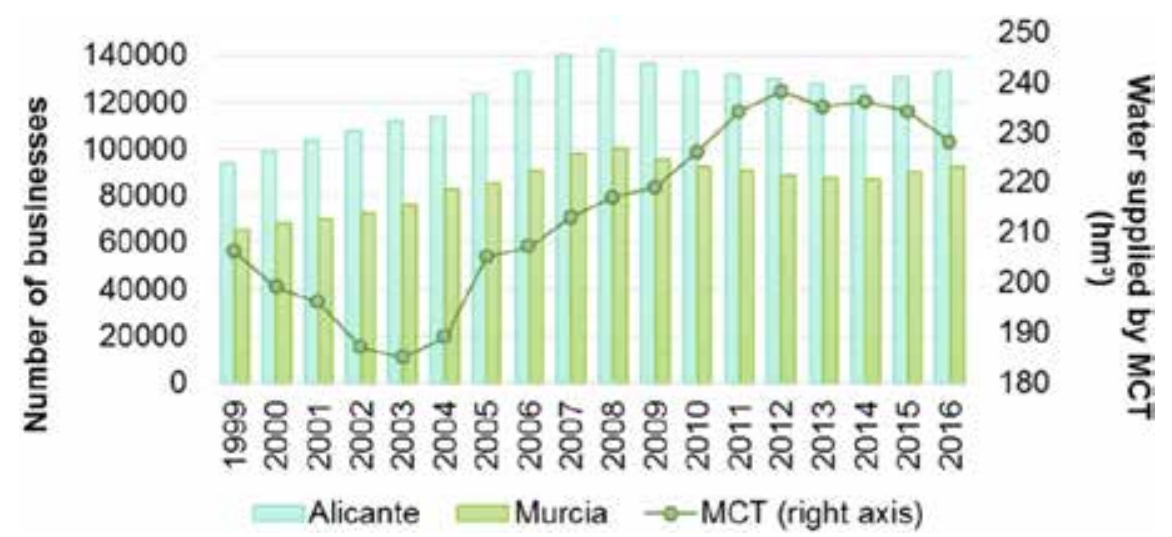

FIGURA 13 - Evolución de los negócios en la región espanhola. FUENTE: Moreno, Ortiz y Aracil (2019).

En relación con el río São Francisco, es un río nacional, federal, que tiene impactos directos en el desarrollo de las regiones por las que pasa, desde su fuente, en la Serra da Canastra, estado de Minas Gerais, hasta su salida al mar. Es el río nacional más grande, es decir, no se comparte con otras naciones cercanas. Su relevancia, como la del río Taibilla en el sureste de España, junto con el trasvase de Tajo-Segura, se ve en las dimensiones económica, social y ambiental.

Desde la generación de energía eléctrica (Figura 13), que fue el primer uso importante que se hizo, con varias plantas instaladas, suministro y producción agrícola, además del turismo y el transporte. Sin embargo, el principal fragilidad que existe a lo largo de este importante río brasileño es la falta de efectividad en la política de saneamiento básico, que todavía resulta en la descarga de aguas residuales en varios puntos de esta fuente (Silva $e t$ al., 2017; Silva, 2020). En sitio web del Comité de la Cuenca de São Francisco (CBHSF) tenemos la siguiente observación:
Las demandas urbanas e industriales, más expresivas en el Alto São Francisco, están relacionadas principalmente con el acero, la minería, los productos químicos, los textiles, el papel y los equipos industriales. Tanto las industrias como las unidades residenciales descargan efluentes indiscriminadamente en las alcantarillas de São Francisco y sus afluentes. Una de las áreas donde la contaminación es más crítica es la Región Metropolitana de Belo Horizonte, donde, además de las aguas residuales domésticas e industriales, existe una alta carga inorgánica por la extracción y procesamiento de minerales. ${ }^{4}$

La Figura 14 ilustra bien la importancia del río São Francisco en el suministro regional urbano, en púrpura, precisamente, los innumerables puntos de captura del agua presentes en regiones con gran riesgo de escasez de agua y que el río ha estado sufriendo grandes variaciones en sus volúmenes a lo largo del tiempo, debido a la irregularidad de las lluvias, los cambios en este régimen de lluvias y el aumento de la evapotranspiración, debido al aumento de las temperaturas.

${ }^{4}$ Disponible en: https://cbhsaofrancisco.org.br/a-bacia/\#socioeconomia. 


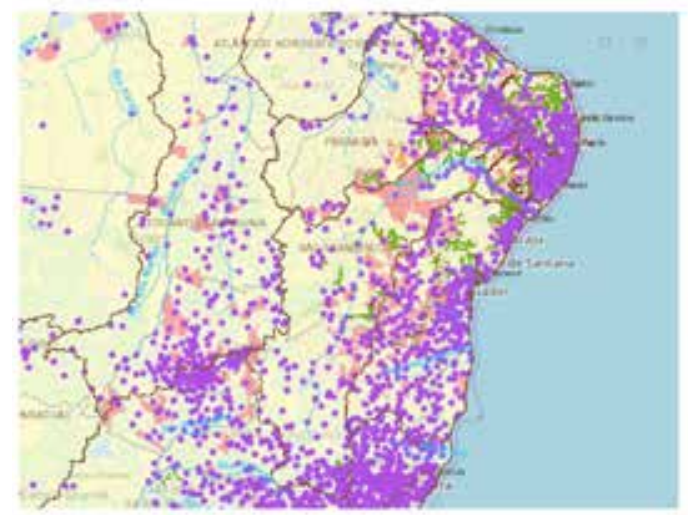

\section{Oferta Urbana}

Flujos superficiales

Suministro Satisfactorio

Expansión del Sistema de Producción

Garantia baja de agua

Sin Información

FIGURA 14 - Extracción de agua en São Francisco para abastecimiento urbano.

FUENTE: Figura gerada e disponível em http://portall.snirh.gov.br/ana/apps/webappviewer/index.

html?id=75fb6a664f5d458bb9a504964e95d1fd

La Figura 15 muestra el uso del agua para actividades industriales, destacando el centro en azul más oscuro, la región de Petrolina, que tiene un expresivo parque industrial, principalmente agroindustrial. Además, es importante señalar que el trasvase tiene dos ejes, figura 2, norte y este, ambos en funcionamiento, cuyas principal ciudade de actividad es Campina Grande, y se está utilizando la agua para el consumo urbano.
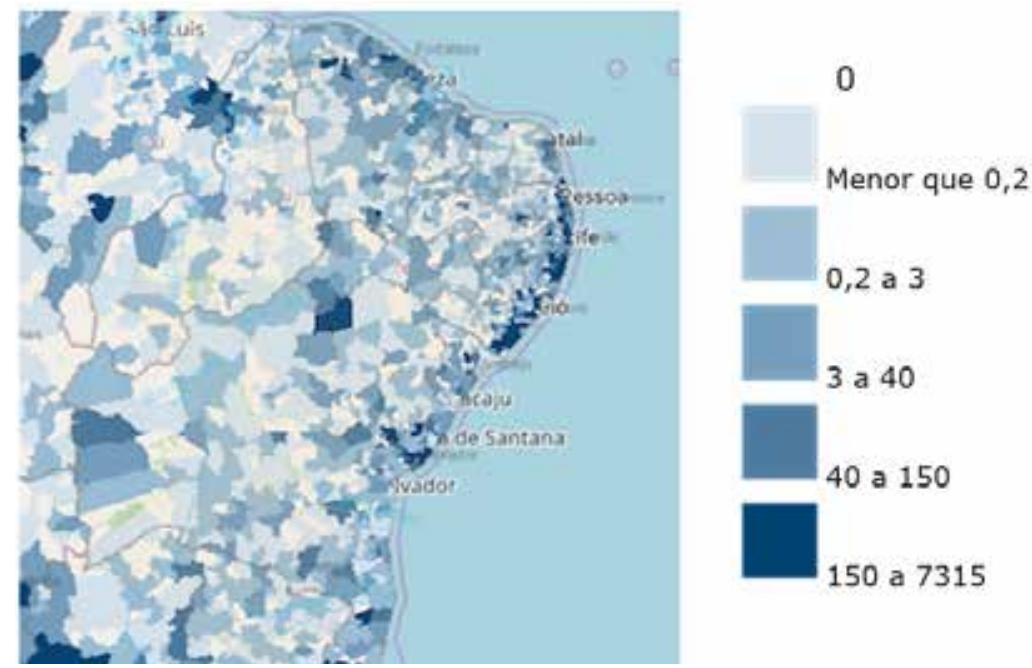

FIGURA 15 - Flujo total de retiro para uso industrial en $2015(1 / \mathrm{s})$

FUENTE: Figura gerada e disponível em http://portall.snirh.gov.br/ana/apps/webappviewer/ index.html?id=724ace05a4bf41be8c2edfle76f66a38 


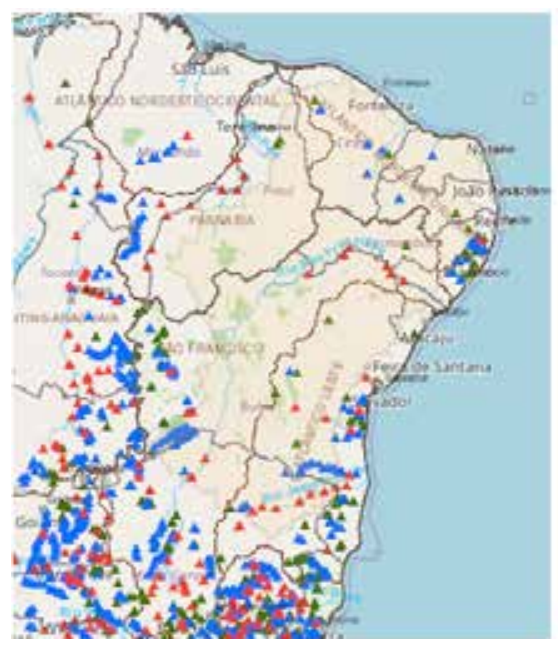

FIGURA 16 - Generacion de Energia Electrica FUENTE: Figura gerada e disponível em http://portall.snirh.gov.br/ana/apps/webappviewer/index. html?id=5094e51beb90418aab741d9dc56ddeb9

\section{Usinas Hidrelétricas - UHE}

\section{Pequenas Centrais Hidrelétricas - PCH}

\section{Centrais Geradoras Hidrelétricas - CGH}

Las Figuras 14, 15 y 16 representan la relevancia del río como un todo, todavía no es un análisis específico del trasvase y su impacto en estas actividades. Hay que tener en cuenta que los análisis preliminares apuntan a una subutilización de la estructura de trasvase del río São Francisco. Básicamente sirven para el consumo humano, lo que puede tener un impacto en la cantidad a cobrar por el uso del agua y el costo final del obra, ya que es necesario considerar el equilibrio entre el monto invertido y los beneficios económicos, sociales y ambientales con esta intervención. (González, 2011; CBHSF, 2018a; 2018b).

No hay datos sobre los impactos del trasvase brasileño en las diversas actividades económicas, sociales y ambientales. Lo que se sabe es que hay un período de sequía, sin lluvia o lluvia concentrada en ciertos momentos, lo que ha colocado a las ciudades pequeñas, medianas y grandes en una situación de escasez de agua que resulta en un uso racionado con el establecimiento de sistemas de rotación en el uso del agua en centros como Campina Grande, que cuenta con casi 400 mil habitantes. Por lo tanto, lo que se hizo más visible fue el colapso del suministro, parcialmente resuelto en esa ciudad, que se normalizó con el inicio del bombeo de agua desde el río São Francisco hasta el embalse conocido como Boqueirão.

Esta incertidumbre o inseguridad en el suministro de agua dificulta la expansión económica de la región, ya que las empresas buscan infraestructura para instalar sus establecimientos. La Figura 18 muestra en general la importancia del riego para Brasil, por región, que cubre el noreste. Además de la Figura 17, se muestra que el riego aún no es una tecnología ampliamente utilizada en las áreas cubiertas por los canales de trasvase, sino principalmente en el centro regional de Petrolina y Juazeiro en Bahía, pero allí no se trata de la influencia del trasvase (Figura 17). 


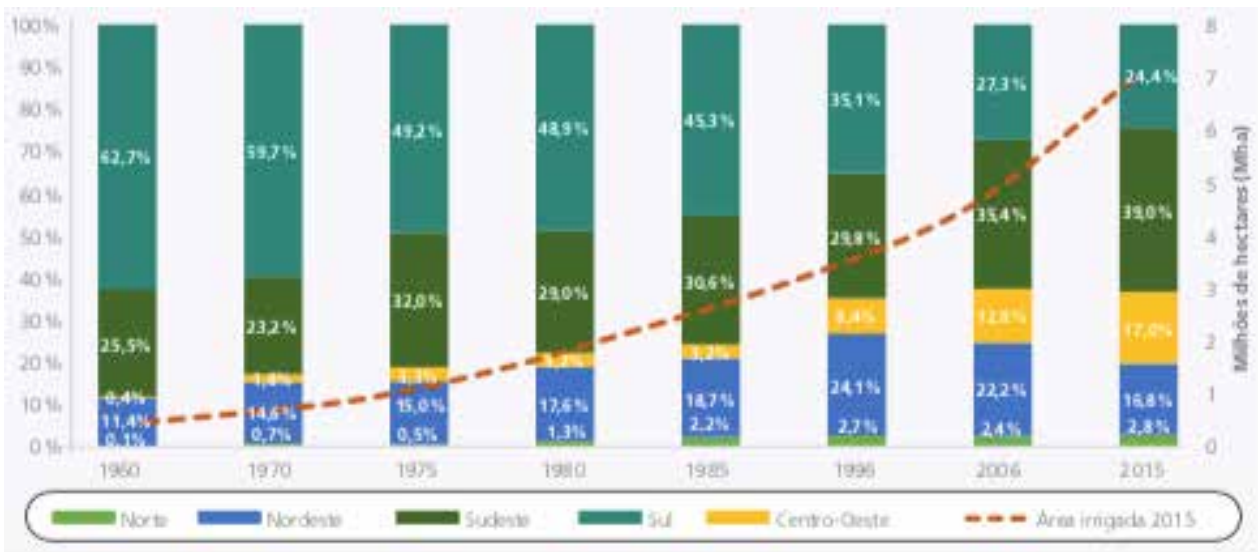

FIGURA 17 - Uso de riego en Brasil. FUENTE: ANA, 2017.

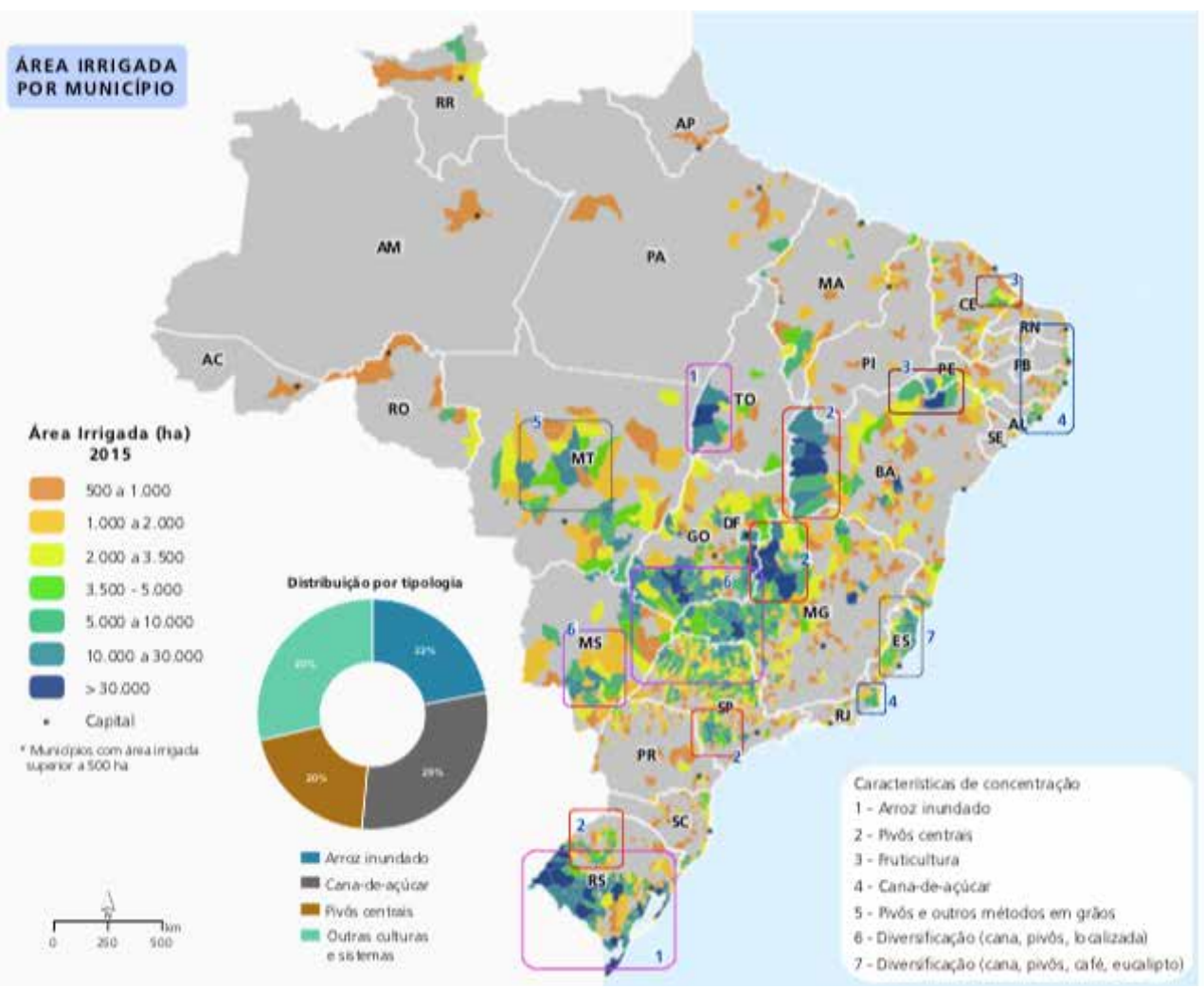

FIGURA 18 - Importancia del riego en Brasil FUENTE: ANA, 2017. 
En relación con el noreste semiárido, la Figura 18 muestra una gran actividad de riego en la parte central, precisamente en el área que no tiene influencia del trasvase, mientras que en el área más al norte todavía hay actividades muy tímidas. Sin embargo, es necesario tener en cuenta que la operación del eje este comenzó en 2018, aunque su propósito central es resolver la escasez de agua de aproximadamente 12 millones de habitantes de esta parte de la región semiárida (Silva, 2016; Brasil, 2004). Pero el gobierno también define otros ejes para ella, como la producción de alimentos, la reactivación de los perímetros de riego, la industria y el turismo, es decir, un proyecto de macrodesarrollo para la región (Brasil, 2004, 2005, 2006, 2009, 2011, 2012).

\section{Entre un trasvase de 40 años y una transposición inacabada: ¿qué se puede aprender?}

La escasez de agua para las actividades desarrolladas por la humanidad es la causa principal de estas intervenciones de infraestructura que se han vuelto sofisticadas con el tiempo pero siempre con el mismo propósito. Por lo tanto, en este punto del artículo pretendemos abordar el aspecto de la gobernanza que parece ser el principal punto de inflexión hoy en el trasvase del río São Francisco. En el punto 3, la gobernanza de ambos países se abordó de manera más general.

Se entiende, por lo tanto, que el semiárido del noreste de Brasil no experimenta un momento de seguridad hídrica en términos de escasez, incluso con el eje este del trasvase funcionando de manera intermitente, ya que no existe un sistema integrado de suministro para todos los municipios que con- forman la vasta región y las reparaciones han sido muy frecuentes. Basado en un sistema integrado con una gobernanza efectiva, que funciona con todos los instrumentos legales vigentes y con una amplia participación de todos los sectores que utilizan el agua, el público, el privado y las universidades, es posible tener un panorama mínimo de gobernanza (Moreno; Ortiz; Aracil, 2019).

En el caso español, como en el caso brasileño, los proyectos de trasvase son seculares. España desde el siglo XIII, con el Reino de Valencia, que buscaba transferir agua entre cuencas en la península ibérica. Sin embargo, esta intención se reanudó en 1537, se discutió durante siglos, a partir de 1780, se reanudó en 1785 y quedó paralizada. El Plan Nacional de Obras Hidráulicas (PNOH) de 1933 insertó el tema en su texto, sin embargo, la guerra civil llegó y detuvo este proceso. Solo en 1959, especialmente en la década de 1960 del siglo pasado, se reanudaron las discusiones sobre el trasvase del Tajo a la cuenca del Segura, en el contexto de la estabilización económica y la posibilidad de transformar el sureste de España en un importante exportador de alimentos. (Moreno y Ortiz, 2009; Moreno y Giménez, 2010). El caso brasileño data del siglo XIX, cuando D. Pedro ordenó los primeros proyectos para que esto sucediera, que solo comenzó a materializarse a fines del siglo XIX y principios del siglo XX. (Silva, 2016).

Al participar en una investigación en la región sureste de España, se puede ver que un punto crucial en la búsqueda de nuevas fuentes de agua fueron las características de la región, a pesar de que tiene una gran costa marina, los procesos masivos con agua desalinizada solo comenzaron a agregar volúmenes al sistemas de suministro en 2003 (Moreno y Ortiz, 2009). Mientras tanto, se necesitaba una solución a 
mediano y largo plazo para la demanda productiva y humana de la región, ya que el problema, según Moreno y Giménez (2010), era estructural, y puede haber formas de mitigar y resolver la escasez. Por lo tanto, el trasvase de agua desde el río Tajo a la cuenca del Segura en el sureste de España fue una solución a los problemas inmediatos e mediatos en la región, que no paralizaron la investigación y la búsqueda de otras fuentes de agua, como se muestra en la Figura 11, porque el agua no es un recurso inagotable y el cambio climático está transformando la dinámica del ciclo del agua en el planeta (Rodell et al., 2018).

Un trasvase tiene varias dimensiones, incluidas políticas, económicas, ambientales y legales. La dimensión económica en el caso de Tajo-Segura llama la atención, ya que su proyecto se desarrolló en base a un eje productivo, considerando el agua como un factor de producción, sujeto a transacciones territoriales y en su uso debe prevalecer la eficiencia, es decir mejor productividad y más racional (Moreno y Ortiz, 2009; Moreno y Nicolás, 2009). En el caso del trasvase de São Francisco, todos los discursos y proyectos se elaboraron dando énfasis al consumo humano, ya que es un principio de la PNRH como ya se mencionó, pero también se embarcó en un programa de desarrollo regional, buscando insertar esta porción de las semiáridas más septentrionales en la ruta de los grandes productores agrícolas, de manera similar a lo que sucede en Petrolina, Pernambuco (Brasil, 2004).

Ambos modelos, aunque tienen diferentes tiempos de operación, se acercan a uno que ha estado en funcionamiento durante 40 años y otro con 2 años de funcionamiento deficiente, con solo un eje funcionando y el otro empezando, es posible mencionar que los conflictos y las controversias fueron parte del contexto y la historia de estas construcciones, con fuerzas a favor y en contra de su realización, especialmente en el campo ambiental.

Un aspecto destacado que debe hacerse pertinente a estas dos importantes intervenciones hidráulicas es la institucionalidad legal. Tanto en el caso español como en el brasileño, sus gobiernos utilizaron el carácter nacional de sus ríos y el dominio público sobre las aguas, lo que les permitió decidir si transponer o no, incluso si hubo momentos formales de participación de las comunidades de usuarios a través de las Confederaciones de Cuenca en España (CBE) y los Comités de Cuenca (CB) en Brasil. Teniendo en cuenta que en el caso brasileño, el comité de la cuenca del río São Francisco se opuso y el Consejo Nacional de Recursos Hídricos estaba a favor del proyecto (Silva, 2016; Silva et al., 2017).

Sin embargo, inicialmente la institucionalización española demostró ser más robusta, principalmente con respecto a la estandarización de las acciones previas y posteriores a el trasvase, es decir, se tuvo en cuenta que una obra de esta magnitud para tener éxito no solo necesitaba las intervenciones de transferencia de agua con la construcción de canales e instalación de estaciones de bombeo $y$ embalses, pero fue necesario establecer el compromiso legal de que las regiones que recibirían las contribuciones de este río estarían completamente preparadas desde el punto de vista del uso de este activo tan valioso como el agua.

Otro punto fue establecer el principio legal de capturar el excedente de agua cuando se transpuso, lo que no existía y no existe hoy en el caso brasileño, ya que lo establecido en la legislación brasileña es precisamente el principio general del mejor uso del agua (Brasil, 1997), mientras que en el modelo 
español había un marco legal específico para el trasvase de aguas, lo que hace una gran diferencia a medida que las reglas del juego se vuelven más claras entre todos.

Es importante destacar la relevancia del Plan Nacional de Obras Hidráulicas (PNOH) en España en 1933, que estableció los principios básicos y las reglas para las intervenciones de ingeniería para buscar el equilibrio hídrico. En el caso brasileño, recién en 2013 llegamos a un plan nacional, que es un instrumento básico para pensar sobre los recursos hídricos de manera unificada. Es importante verificar en la lectura de este plan español cuán lejos se adelantó a su tiempo para establecer relaciones entre la distribución de las precipitaciones y las tasas de evaporación del agua en todo el territorio, con énfasis en la región de Alicante y Murcia con bajas precipitaciones y altos indicadores de evaporación del agua, siendo una región de regímenes fluviales indefinidos (PNOH, 1933). Sin embargo, un punto que llamó la atención en la investigación sobre el territorio español fue la preocupación por los volúmenes de agua que se desperdician, que sobran, ya sea no simplemente usándola o saliendo de las aguas del Mediterráneo y el Atlántico.

Por lo tanto, existe la percepción de que el uso racional de todo el potencial hídrico debe ser el pilar de una política hídrica, incluso si estamos en un entorno de falsa abundancia de agua como en Brasil, ya que, aunque el semiárido del noreste ya experimentó escasez como algo cíclico, la crisis del agua comenzó a plagar otras regiones como el sureste, el centro económico brasileño y el norte de la amazonia, el centro de la biodiversidad. Es hora de pensar en el balance hídrico como una premisa básica del agua, la justicia ecológica y social.
Se destaca el dispositivo de la Constitución brasileña de 1988, específicamente el art. 3 y los ítems II y III, en los cuales el primero coloca el desarrollo nacional como la base de la República de Brasil y el segundo inserta un complemento con otro pilar, la reducción de las desigualdades regionales, de donde se puede extraer que llevar a cabo un proceso de reequilibrio del agua sería totalmente esencial, vinculante y posible en la perspectiva jurídica brasileña (Brasil, 1988).

El plan español, ya en 1933, suscita preocupación por la provincia de Alicante como gravemente afectada por este desequilibrio hídrico muy intenso (PNOH, 1933). Para eso, el plan ya incluía la derivación de las aguas del río Tajo, es decir, la extracción de agua del orden de 7 millones de $\mathrm{m}^{3}$, que se consideraban poco o no utilizados, para ser insertados en la cuenca del Segura, lo que beneficiaría sustancialmente este región, que en realidad ocurrió de acuerdo con las Figuras 11, 12 y 13. El plan hidrológico español busca lanzar principios y acciones para reducir las diferencias regionales.

El plan brasileño no fue tan asertivo, ya que no lanzó principios más específicos, pero aparentemente la operatividad institucional del agua aún no se ve con la debida importancia o el debido carácter nacional (Silva, 2020). La ausencia de un tratamiento legal específico y más quirúrgico en relación con el exceso de agua es un síntoma de esto, ya que tenemos un país de gran extensión y con un gran potencial hídrico. Sin embargo, en ambas obras, la gran tensión existente está en relación con el tema ambiental, la modificación de los ecosistemas, la falta de agua para los ecosistemas, aunque la toma de agua tanto en el río Tajo como en el río São Francisco es excedente de agua a la cuenca (Brasil, 2004; Moreno y Giménez, 2010), deben tenerse en 
cuenta los impactos socioambientales y corresponde a los sectores gubernamentales específicos proceder con los procesos de revitalización de las cuencas y el monitoreo de las mismas.

Otro punto de institucionalidad es que nuestra legislación no menciona la necesidad de establecer un mínimo de agua para el mantenimiento de los ecosistemas, que en las leyes de los países de origen hispano y en la propia España adoptan el concepto de caudales ecológicos. Es como, por ejemplo, licenciar una obra para recolectar agua de una determinada fuente para abastecer una ciudad o región metropolitana, el flujo se calcularía teniendo en cuenta una cantidad límite que debe estar disponible para mantener los ecosistemas. Nuestra Política Nacional de Recursos Hídricos y la Política Nacional de Saneamiento Básico tienen como base la protección del medio ambiente, sin embargo, esto se pone de una manera muy genérica, dejando muchas acciones a desarrollar a través de ordenanzas, instrucciones normativas y resoluciones.

Según Giménez (2019), al analizar el sistema legal español, afirma que el flujo ecológico, entendido como el flujo mínimo de circulación necesario para el mantenimiento de la flora y la fauna de los ríos, también se considera una prioridad; de hecho, no se trata como un uso, sino como una restricción de los sistemas de exploración, y debe ser arreglado por los organismos que participan en la gestión y gobernanza del agua, en el caso español hablamos de planificación hidráulica que, en nuestra opinión, expresa mejor los fundamentos. Estructuración de una Ley de Aguas que tiene uno de sus pilares en el ciclo urbano del agua. En el caso español, este flujo debe corregirse durante la fase de planificación (Irujo, 1994).
En el caso de Brasil, la Política Nacional Ambiental (PNMA), ley n ${ }^{\circ} .6 .938 / 1981$, tiene en la licencia de uno de sus instrumentos más importantes que el Estado debe utilizar siempre que haya una actividad potencialmente contaminante o que pueda causar un impacto considerable en la naturaleza, como la construcción de trasvases $\mathrm{y}$, junto con otro instrumento no menos importante de la PNRH, el subsidio, que permite al gobierno establecer flujos de agua, la cantidad que se puede extraer o no de un cuerpo de agua dado. Además, es interesante notar que la Corte Suprema española emitió una decisión, n. 309/2019 del 11 de marzo, obligando al Gobierno a establecer los niveles o regímenes relacionados con los flujos ecológicos o los flujos ecológicos, que requieren un nivel de flujo real y científicamente validado (Tribunal Supremo - Sala Tercera, de lo Contencioso-Administrativo, $n$. 309/2019 de 11 de março).

En la práctica, esta decisión anuló la provisión del Plan Hidrológico, conocido como el Plan de Cuenca en Brasil, que requiere que se realice un nuevo estudio para actualizar los valores de los flujos ecológicos con el fin de satisfacer las verdaderas necesidades de la cuenca del Tajo, y no aceptó la solicitud de una de las partes interesadas que le pidió a la corte que establezca estos valores de flujo. Sin embargo, el tribunal entendió que esta es una tarea que corresponde a la planificación hidráulica y, por lo tanto, corresponde al Gobierno establecer estos valores. Sucede que en España la Ley del Agua está mejor estructurada dentro de una visión administrativa que forma el campo de la Administración Pública del Agua o la Administración Pública Hidráulica.

Por lo tanto, se considera que esta tradición legal en el campo de la gestión y gobernanza del 
agua fue un diferencial para la implementación del trasvase y su operación en varios frentes, principalmente en la producción agrícola y la generación de empleos e ingresos, así como en el suministro humano, que fueron decisivos para el desarrollo regional del sureste del mediterráneo. La Tabla 1 muestra la línea histórico-legal de las reglas específicas para el trasvase del agua en España, lo que no ocurrió en Brasil, con discusiones mucho más en el campo político en las arenas respectivas como los $\mathrm{CB}$ y la CNRH, que aparentemente colabora con la incertidumbre legal del obra brasileña y promueve la incertidumbre en el uso del agua disponible mientras fluye y se usa solo para el suministro humano, lo que ciertamente corrobora el aumento en el valor final del obra y el agua utilizada, recordando que los canales necesitan ser mantenidos y operados correctamente.
Por lo tanto, existe una baja institucionalidad en el trasvase de São Francisco, lo que resulta en una baja transparencia y reglas para que los actores involucrados puedan actuar. Otro punto que debe destacarse como un elemento a observar para un buen funcionamiento del trasvase de São Francisco es la organización de un órgano de gestión específico, en el caso de Tajo-Segura, se crearon los siguientes órganos (Moreno y Gimenéz, 2010):

- La Comisión Central de Exploración: este organismo es responsable de establecer las cuotas a explotar, aumentar las tarifas, cuidar del equilibrio hidrográfico de los embalses;

- Las confederaciones hidrográficas de Tajo-Segura: gestión técnica y económica de la explotación de la infraestructura hidráulica, en la parte correspondiente a la sección de

TABLA 1 - Evolución histórico-legal de la transposición Tajo-Segura.

\begin{tabular}{|c|c|}
\hline Legislación & Contenido \\
\hline Ley 21/1971, de 19 de junio & Aprovechamiento conjunto de los ríos Tajo y Segura \\
\hline Real Decreto 1982/1978, de 26 de julio & $\begin{array}{l}\text { Organización de los servicios encargados de gestionar la explotación } \\
\text { de la infraestructura hidráulica "Trasvase Tajo-Segura" }\end{array}$ \\
\hline Ley 52/1980, de 16 de octubre & $\begin{array}{l}\text { Ley de régimen económico de la explotación del acueducto Tajo- } \\
\text { segura }\end{array}$ \\
\hline Real Decreto 2530/1985, de 27 de diciembre & $\begin{array}{l}\text { Régimen de explotación y distribución de funciones en la gestión } \\
\text { técnica y económica del "acueducto Tajo-Segura" }\end{array}$ \\
\hline Real Decreto Ley 8/1995, de 4 de agosto & $\begin{array}{l}\text { Medidas urgentes de mejora del aprovechamiento del } \\
\text { trasvase Tajo-Segura }\end{array}$ \\
\hline $\begin{array}{l}\text { Ley } 24 / 2001 \text {, de } 27 \text { de diciembre, de Medidas Fiscales, } \\
\text { Administrativas y del Orden Social }\end{array}$ & Modificación de la ley 52/1980 \\
\hline Real Decreto 1241/2012, de 24 de agosto & $\begin{array}{l}\text { Se adoptan medidas administrativas excepcionales de gestión de los } \\
\text { recursos hidráulicos para superar los efectos de la interrupción parcial } \\
\text { del suministro mediante la infraestructura del trasvase Tajo-Segura en } \\
\text { la cuenca hidrográfica del Segura. }\end{array}$ \\
\hline
\end{tabular}

FUENTE: elaboración propia a partir de site https://www.chsegura.es/chs/cuenca/infraestructuras/postrasvaseTajoSegura/legislacion.html, Confederação Hidrográfica do Segura. 
conducción, desde la entrada en el río Tajo hasta el desagüe en el embalse de Talave;

- La Unión Central de Riego: administración corporativa en el sentido de defender los regantes;

- La Comunidad del Canal de Taibilla: es un organismo autónomo, con personalidad jurídica propia, aunque con relaciones de dependencia funcional en relación con el Ministerio del Medio Ambiente. Su función básica es organizar la distribución de los flujos de descarga a los suministros urbanos correspondientes, entregando el agua a las entidades locales competentes para la distribución.

Moreno (1997) ya analiza el trasvase de Tajo-Segura como inevitable para la supervivencia de las comunidades en esa región, no solo un problema restringido a España, sino una demanda de la propia Unión Europea con respecto al suministro de alimentos producidos en esa región. Entonces, se estableció la institucionalidad y hoy existe una perspectiva democrática en la gestión. El hecho es que el obra fue fundamental para el equilibrio hídrico de las regiones con poca o ninguna agua. Sin embargo, es importante pensar en lo que dice Seguido y Amorós (2018) sobre la finitud de los recursos hídricos, incluso con los trasvases, siempre será necesario pensar en sistemas complementarios para que haya un equilibrio, incluso teniendo en cuenta que la demanda crece.

Además, en 2018, se estableció el Pacto Provincial del Agua de Alicante (Moreno y Gimenéz, 2018), que tenía como objetivo reunir a todos los actores para reconocer que el déficit hídrico existe, pero las soluciones hidráulicas han ayudado a superar los problemas, sin embargo, aún permanecen trabajos posteriores a el trasvase que deben com- pletarse, además de la necesidad de reconocer la sobreexplotación de los acuíferos como un problema ambiental importante, así como el déficit en energías renovables, mantener la agricultura de manera sostenible, mantener el suministro urbano, invertir más en desalinización como uno sistema complementario, invertir en la purificación y reutilización del agua, buscar ahorros y eficiencia de todo el sistema, deseando sostenibilidad económica e interconexiones entre cuencas. Se sabe que esta obra fue estratégica, a pesar de todas las críticas, pero que cada vez es más necesario reducir la incertidumbre que existe cada año con respecto a los volúmenes a transferir, lo que influye directamente en los mercados y las empresas regionales (Moreno, 2010).

Además, es importante tener en cuenta que en el caso de Tajo-Segura, se estableció un sistema de compensación completo para las comunidades autónomas que forman parte de la cuenca del Tajo y que donan agua al sistema. Por lo tanto, la ley $\mathrm{n}$. 52/1980 estableció que para mantener el sistema sería necesario considerar tres factores: amortización de gastos con el sistema, gastos operativos fijos y gastos operativos variables. Luengo (2017) argumenta que existe una responsabilidad ambiental que debe resolverse y que busca el equilibrio económico del trasvase.

\section{Consideraciones finales}

Este ensayo presentó una reflexión más general y específica sobre las principales intervenciones hidráulicas que tienen un impacto directo en el desarrollo regional de numerosos territorios alrededor del mundo. Asumimos la tarea de traer dos sistemas que son similares. Se encontró en esta investigación, 
cuyos resultados se informan aquí, la percepción de que todavía no existe un modelo brasileño de gobernanza de trasvase implementado de manera concreta y que existe una subutilización del sistema que se utiliza exclusivamente para el suministro humano, específicamente en relación con el eje este está trabajando con varios problemas de parada para correcciones entre otros problemas operativos.

Es importante señalar que el principal problema que surge, incluso frente a esta subutilización del trasvase, está en las infraestructuras posteriores a la transferencia, es decir, los sistemas utilizados para que el agua llegue al usuario, porque la gran promesa del obra fue resolver el problema de 12 millones de habitantes, pero es común ver en las noticias y otras fuentes la falta de agua en diferentes ciudades y la falta de aguas residuales tratadas. Las cosas no están claras, las reglas del juego no están detalladas como en el caso español, que todavía tiene problemas, sin embargo, tiene un cierto nivel de institucionalidad, lo que ayuda a visualizar las formas de salir de los conflictos.

En Brasil, hay un río nacional, que ahora se está vertiendo en otras cuencas en otros estados, lo que genera dudas sobre el dominio del agua, ya que el río São Francisco es federal y está entrando en los canales de otros estados que tienen una deficiencia de agua muy alta y el gobierno federal quiere una mayor participación de los estados en la gestión y gobernanza de los canales. Sin embargo, si se siguiera el modelo español, ya tendría un modelo ensamblado cuando empezó las operaciones en 2018, lo que no ha sucedido hasta ahora. La inauguración se llevó a cabo sin un modelo específico y continúa sin. Por supuesto, estamos hablando de un proyecto cuya duración es dos veces mayor que la de España, que ejerce presión sobre la necesidad de un modelo de gobernanza que pueda ampliar sus usos y establecer compromisos sociales y ambientales.

Por lo tanto, hay algunos aspectos destacados que no se han llevado a cabo: modelo de gobernanza; costos operativos no detallados, esto incluye el costo de la energía utilizada para bombear para superar obstáculos geográficos; los otros usos del agua, ya que por ahora solo se usa para consumo urbano; La infraestructura de las ciudades para recibir agua, independientemente del tamaño y el suministro de agua a las poblaciones rurales.

Incluso con el eje este funcionando, se nota un ambiente de escasez hidrosocial, una expresión utilizada por Swyngedouw (2004; 2013) para justificar el uso selectivo del agua, que, en el caso del trasvase brasileña, la necesidad de resolver la crisis del agua en ciudades medianas como Campina Grande fue esencial para acelerar la finalización de esta parte del obra, incluso sin tener en cuenta un sistema posterior a lo trasvase y la consiguiente recepción de las aguas, incluida la revitalización de las cuencas receptoras. Las actas y documentos del Ministerio Público de la Federación demuestran que el obra del eje este, está inacabado. Todavía habría un vacío de gobernanza, que se considera el primer elemento para poder apuntar destino al agua aportada. (MPF, 2017; Justiça Federal, 2019).

En 2017, el Ministerio Público Federal (MPF) recomendó que el Instituto Brasileño del Medio Ambiente (IBAMA) no otorgue la licencia de operación debido a problemas en los trabajos posteriores a el trasvase, como el saneamiento de las ciudades (MPF, 2017). Recientemente, en 2019, el Tribunal Federal determinó que los organismos competentes realizan informes de seguridad en las represas, en vista de las interrupciones que han ocurrido y el 
riesgo potencial de nuevas interrupciones (Justiça Federal, 2019).

La única perspectiva legal de gobernanza que existía era en relación con el Programa de Revitalización de São Francisco, instituido por el Decreto no. 8.834, del 9 de agosto de 2016, que fue revocado en febrero por el actual presidente. Por lo tanto, se entiende que existe una necesidad urgente de adoptar un modelo de gobernanza específico para el trasvase brasileño, dadas sus características peculiares, involucrando a todos los actores interesados, como en el modelo español, y no es posible aplicar solo principios y reglas establecidos en otro contexto como es el caso de la PNRH, cuando no había el trasvase de agua tan complejo.

Por lo tanto, este modelo debe tener las siguientes características: participación, descentrali- zación, base ecológica, elaborar un plan de uso del agua para el sector productivo, pensar en los flujos y los diferentes escenarios climáticos futuros, incluir el consumo y el suministro urbano y rural. Incluye las poblaciones de pueblos pequeños que buscan el objetivo del agua universal, así como también a proporcionar a las regiones sistemas de tratamiento y reutilización del agua. Sin embargo, es necesario enfatizar la necesidad de invertir en investigación y tecnología en busca de más fuentes de agua, solo el trasvase no resuelve completamente el problema del desequilibrio hídrico.

\section{Reconocimiento}

Agradecemos a CAPES por la ayuda financiera para la investigación.

\section{Referencias}

Agência Nacional de Água (ANA). Atlas irrigação: uso da água na agricultura irrigada. Brasília: ANA, 2017.

Brasil. Constituição da República Federativa do Brasil. Brasília: Senado Federal, 1988.

Brasil. Lei n. 9.433, de 8 de janeiro de 1997. Brasília: Senado Federal, 1997.

Brasil. Ministério da Integração Regional. Plano estratégico de desenvolvimento sustentável do semiárido. Brasília: MIR, 2005.

Brasil. Ministério do Meio Ambiente. Plano de ações estratégicas e integradas para o desenvolvimento do turismo sustentável na bacia do Rio São Francisco. Brasília, MMA, 2006.

Brasil. Ministério da Integração Nacional. Programa de desenvolvimento integrado e sustentável do semi-árido. Brasília: SPR, 2009.
Brasil. Superintendência de Desenvolvimento do Nordeste. Plano regional de desenvolvimento do nordeste. Recife: Sudene, 2011.

Brasil. Ministério da Integração Nacional. I Conferência Nacional de Desenvolvimento Regional. Brasília: SDR, 2012.

Brasil. Ministério da Integração Nacional. Projeto de integração do Rio São Francisco com Bacias Hidrográficas do Nordeste Setentrional. Relatório de Impacto Ambiental - RIMA. Brasília: Ministério do Desenvolvimento Regional, 2014. Disponible en: <http://www.integracao.gov.br/ saofrancisco/integracao/rima.asp $>$.

Brasil. Ministério da Integração Nacional. Projeto de integração do Rio São Francisco com Bacias Hidrográficas do Nordeste Setentrional. Relatório de Impacto Ambiental - RIMA. Disponible en: <http://www.integracao.gov.br/ saofrancisco/integracao/rima.asp $>$. 
Brasil. Ministério das Cidades. Secretaria Nacional de Saneamento Ambiental - SNSA. Sistema Nacional de Informações sobre Saneamento: Diagnóstico dos Serviços de Água e Esgotos. 2015. Brasília: SNSA/MCIDADES, 2017.

CBHSF - Comitê de Bacia Hidrográfica do São Francisco. Gestão e Operação do Projeto de Integração do Rio São Francisco com Bacias Hidrográficas do Nordeste Setentrional (PISF). Relatório, 2018a. Disponible en: <https://cdn. agenciapeixevivo.org.br/media/2019/07/Gestão-do-PISF-volume-2-1.pdf $>$.

CBHSF - Comitê de Bacia Hidrográfica do São Francisco. Gestão e Operação do Projeto de Integração do Rio São Francisco com Bacias Hidrográficas do Nordeste Setentrional (PISF). Relatório, 2018b. Disponible en: <https://cdn. agenciapeixevivo.org.br/media/2019/07/Relatório-Técnico-PISF-Rev-02-1.pdf $>$.

Correia, A. F.; Farias, T. Governança metropolitana: desafios para a gestão metropolitana fluminense. Revista de Direito Ambiental, 78, 447-474, 2015.

Diniz, C. C. Celso Furtado e o desenvolvimento regional. Nova Econ., Belo Horizonte, 19(2), 227-249, Sept. 2009. doi: 10.1590/S0103-63512009000200001.

Echaid, J. El derecho humano al agua potable y los tratados de protección recíproca de inversiones. $406 \mathrm{p}$. Buenos Aires, Tese (Doctorado en Derecho) - Facultad de Derecho, Universidad de Buenos Aires, 2013.

Frey, M. R.; Wittmann, M. L. Gestão ambiental e desenvolvimento regional: uma análise da indústria fumageira. EURE, Santiago, 32(96), 99-115, ago. 2006. doi: 10.4067/ S0250-71612006000200006.

Geiger, F. El sureste español e los problemas de la aridez. Revista de Geografia, 7, 166-209, 1973.

Gimenéz, A. M. Los caudales ecológicos en la planificación hidrológica. Reflexiones a la luz de la Sentencia del Tribunal Supremo 309/2019 de 11 de marzo, relativa al plan hidrológico del Tajo y sus posibles impactos en el Trasvase Tajo-Segura. Sostenibilidad: económica, social y ambiental, 1, julio 2019.

González, E. S. M. Un análisis económico de los trasvases de agua intercuencas: el trasvase tajo-segura. Tesis (Doctoral) - Universidad Nacional de Educación à Distancia, 2011.
Granito, R. A. N.; Mantovani, D. M. N.; Cunha, J. A. C. da; Rodrigues, S. da S.; Basílio, A. C. L. Desenvolvimento regional e novos paradigmas: iniciativas de promoção do desenvolvimento na comunidade da Mangueira. Cad. EBAPE. $B R$, Rio de Janeiro, 5(2), 1-14, June 2007. Disponible en: http://www.scielo.br/scielo.php?script=sci_arttext\&pi$\mathrm{d}=\mathrm{S} 1679-39512007000200006 \& \operatorname{lng}=\mathrm{en} \& \mathrm{nrm}=$ iso

Guimarães Filho, C.; Cunha, T. J. F.; Teixeira, A. H. de C.; Correia, R. C.; Sá, I. B.; Pereira, L. A.; Brito, L. T. de L.; Kiil, L. H. P.; Moura, M. S. B. de; Silva, P. C. G. da. Caracterização do Semiárido brasileiro: fatores naturais e humanos. Petrolina: Embrapa Semiárido, 2010.

Irujo, A. E. Usos del agua e impacto ambiental: evaluación de impacto ambiental y caudal ecológico. Revista de Administración Pública, 134, 109-154, 1994.

Justiça Federal. Decisão. Processo no: 080019946.2017.4.05.8203 - Ação Civil Pública. 11 ${ }^{\mathrm{a}}$ Vara Federal, Monteiro. Disponible en: $<$ https://pje.jfpb.jus.br/pje/Painel/ painel_usuario/documentoHTML.sea>.

López, J. B.; Passera, C. B.; Rebolla, J. L. G.; Cruz, A. B. R. Pastos de zonas áridas y semiáridas del sudeste Ibérico. Arch. Zootec., 50, 501-515, 2001.

Luengo, A. Réplica al artículo "Mitos y realidades sobre el Trasvase Tajo-Segura". In: IAGUA, 21 de fevrero de 2017. Disponible en: $<$ https://www.iagua.es/blogs/antonio-luengo/ replica-al-articulo-mitos-y-realidades-trasvase-tajo-segura>

Martínez, A. P.; Cuervo, J. A. L. Importancia del trasvase Tajo-Segura en el abastecimiento del Sureste Español. In: Moreno, J. M. El Trasvase Tajo-Segura: repercusiones económicas, sociales y ambientales en la Cuenca del Segura. Alicante: Instituto Universitario del Agua y Ciencias Ambientales, 2009.

Martínez-Valderrama, J.; Martínez, S.; Ibánez, J. Un sistema de Alerta Temprana (SAT) de la desertificación en España mediante modelos de Dinámica de Sistemas. An early warning system for desertification in Spain through System Dynamics modelling. In: Anais del X Congreso Latinoamericano de Dinámica de Sistemas, 2010.

Mattedi, M. A.; Theis, I. M. Cruzando fronteiras: conhecimento e interdisciplinaridade na pesquisa em desenvolvimento regional. Revista Redes, 7(2), 77-94, 2002. 
MPF - Ministério Público Federal. Recomendação ${ }^{\circ}$ 13/2017. Inquérito Civil $n^{\circ}$ 1.24.004.000005/2017-61. Município de Monteiro, Paraíba. Disponible en: <http:// www.mpf.mp.br/pb/sala-de-imprensa/docs/recomendacao-13-2017>.

Moreno, J. M. El trasvase Tajo-Segura, en el centro de la tormenta política de la transición. Revista Internacional de Ciencias Sociales, 17, 21 jan. 1997.

Moreno, J. M. Balance económico del trasvase Tajo-Segura. Disponible en: <http://www.cervantesvirtual.com/nd/ ark:/59851/bmc12662>. Alicante: Biblioteca Virtual Miguel de Cervantes, 2001.

Moreno, J. M.; Giménez, A. M. Incidéncia del Trasvase Tajo-Segura en la Provincia de Alicante. Alicante: Fundación de la CV Agua y Progreso, 2010.

Moreno, J. M.; Giménez, A. M. Pacto provincial del agua Alicante. Alicante: Diputación Povincial de Alicante, 2018.

Moreno, J. M.; Ortiz, M. I. L. Historia del trasvase Tajo-Segura. In: Moreno, J. M. (Org.). El Trasvase Tajo-Segura: repercusiones econômicas, sociales y ambientales en la Cuenca del Segura. Alicante: Instituto Universitario del Agua y Ciencias Ambientales, 2009.

Moreno, J. M.; Ortiz, M. I. L.; Aracil, P. F. Water distribution management in South-East Spain: A guaranteed system in a context of scarce resources. Science of the Total Environment, 648, 1384-1393, 2019.

Moreno, J. P.; Nicolás, J. J. Martínez. Influencia económica del transvase Tajo-Segura en la agricultura de las províncias de Murcia, Alicante y Almería. In: Moreno, J. M. (Org.). El Trasvase Tajo-Segura: repercusiones económicas, sociales y ambientales en la Cuenca del Segura. Alicante: Instituto Universitario del Agua y Ciencias Ambientales, 2009.

Ortega, C. V.; Hernández-Mora, N. Institutions and institutional reform in the Spanish water sector: A historical perspective. In: Garrido, A.; Llamas, M. Water Policy in Spain. CRC Press, 2009. p. 137-150.

Parlamento Europeu. Directiva 2000/60/CE do Parlamento Europeu e do Conselho. Jornal Oficial das Comunidades Europeias, 22.12.2000.
PNOH - Plan Nacional de Obras. Ministerio de Obras Publicas. Centro de Estudios hidrograficos. Tomo I e Tomo II. Exposisión General, M. Lorenzo Pardo, España, 1933.

Ribeiro, N. B.; Johnsson, R. M. F. Discussões sobre a governança da água: tendências e caminhos comuns. Ambient. Soc., São Paulo, 21, e01252, 2018. doi: 10.1590/1809-4422asoc0125r2vu1811ao

Rodell, M.; Famiglietti, J. S.; Wiese, D. N.; Reager, J. T.; Beaudoing, H. K.; Landerer, F. W.; Lo, M. H. Emerging trends in global freshwater availability. Nature, 557, 651$659,2018$.

Rupiz-Puga, P.; Vázquez-Alarcón, A.; Hernández-Garcia, M. A.; Granados-Sánchez, D. Los procesos de desertificación y las regimens áridas. Revista Chapingo. Serie Ciencias Forestales y del Ambiente, Chapingo, México: Universidad Autónoma Chapingo, 19(1), 45-66, enero-abril, 2013.

Santana, S. C. de J. Avaliação das alterações da qualidade da água em função das variações de vazões no baixo curso do rio São Francisco. 206 f. Salvador, Tese (Doutorado em Química) - Programa de Pós-Graduação em Química, UFBA, 2012.

Seguido, A. F. M.; Amorós, A. M. R. Perspectivas de funcionamiento del trasvase Tajo-Segura (España): efectos de las nuevas reglas de explotación e impulso de la desalinización como recurso sustitutivo. Boletín de la Asociación de Geógrafos Españoles, 79(2754), 1-43, 2018. doi: 10.21138/ bage. 2754 .

Silva, J. I. A. O. Ressignificação Ambiental e modernização ecológica no Semiárido: o projeto de integração e revitalização do São Francisco. 1. ed. São Paulo: Hucitec, 2016.

Silva, J. I. A. O. Segurança Hídrica Ecológica: fundamentos para um conceito jurídico. João Pessoa, Tese (Doutorado em Direito) - Universidade Federal da Paraíba, 2020.

Silva, J. I. A. O.; Farias, T. Q.; Cunha, B. P. da. A integração do rio São Francisco, saneamento, resíduos sólidos e água: algumas linhas de análise sobre o direito às cidades sustentáveis. Revista de Direito da Cidade, [S.1.], 9(3), 1085-1119, jul. 2017. doi: 10.12957/rdc.2017.28200 
Silva, S. C.; Ferreira, T.; Pompeo, M. L. M. Diretiva Quadro D'Água: uma revisão crítica e a possibilidade de aplicação ao Brasil. Ambient. Soc., São Paulo, 16(1), 39-58, Mar. 2013. doi: 10.1590/S1414-753X2013000100004

Swyngedouw, E. Social Power and the Urbanization of Water. Flows of Power. Oxford: Oxford University Press, 2004.

Swyngedouw, E. Águas revoltas: a economia política dos serviços públicos essenciais. In: Castro, J. E.; Heller, L. Políticas públicas e gestão de serviços de saneamento. Belo Horizonte: Ed. UFMG; Rio de Janeiro: Ed. FioCruz, 2013.
Water Risk Atlas. Disponible en: <https://www.wri.org/ applications/aqueduct/water-risk-atlas/\#/advanced=false\&basemap $=$ hydro\&indicator $=$ w_awr_def_tot_cat\&la$\mathrm{t}=30 \& \operatorname{lng}=-80 \& \operatorname{mapMode}=$ view $\&$ month $=1$ \&opacity $=-$ $0.5 \&$ ponderation $=$ DEF\&predefined $=$ false $\&$ projection $=\mathrm{ab}-$ solute \&scenario $=$ optimistic $\&$ scope $=$ baseline $\&$ timeScale $=$ annual\&year $=$ baseline $\&$ zoom $=3$ World $>$. Resource Institute, 2019. 